\title{
Type III Neuregulin-1 Is Required for Normal Sensorimotor Gating, Memory-Related Behaviors, and Corticostriatal Circuit Components
}

\author{
Ying-Jiun J. Chen, ${ }^{1}$ Madeleine A. Johnson, ${ }^{2}$ Michael D. Lieberman, ${ }^{3}$ Rose E. Goodchild, ${ }^{4}$ Scott Schobel, ${ }^{8}$ \\ Nicole Lewandowski, ${ }^{3}$ Gorazd Rosoklija, ${ }^{8,9}$ Ruei-Che Liu, ${ }^{7}$ Jay A. Gingrich, ${ }^{8}$ Scott Small, ${ }^{4}$ Holly Moore, ${ }^{8}$ \\ Andrew J. Dwork, ${ }^{1,8,9}$ David A. Talmage, ${ }^{5,6}$ and Lorna W. Role ${ }^{1,2,3,5}$ \\ ${ }^{1}$ Department of Cell Biology and Pathology, ${ }^{2}$ Center for Neurobiology and Behavior, ${ }^{3}$ Integrated Program in Cellular, Molecular, and Biophysical Studies, \\ ${ }^{4}$ Department of Neurology, ${ }^{5}$ Institute of Human Nutrition, ${ }^{6}$ Department of Pediatrics, College of Physicians and Surgeons, and ${ }^{7}$ Department of Biostatistics, \\ School of Pubic Health, Columbia University, and Departments of ${ }^{8}$ Psychiatry and ${ }^{9}$ Neuroscience, New York State Psychiatric Institute, New York, New \\ York 10032
}

\begin{abstract}
Neuregulin-1 (Nrg1)/erbB signaling regulates neuronal development, migration, myelination, and synaptic maintenance. The Nrg1 gene is a schizophrenia susceptibility gene. To understand the contribution of Nrg1 signaling to adult brain structure and behaviors, we studied the regulation of type III Nrg1 expression and evaluated the effect of decreased expression of the type III Nrg1 isoforms. Type III $\mathrm{Nrg} 1$ is transcribed by a promoter distinct from those for other $\mathrm{Nrg} 1$ isoforms and, in the adult brain, is expressed in the medial prefrontal cortex, ventral hippocampus, and ventral subiculum, regions involved in the regulation of sensorimotor gating and short-term memory. Adult heterozygous mutant mice with a targeted disruption for type III $\mathrm{Nrg} 1\left(\mathrm{Nrg} 1^{\mathrm{tm} 1.1 \mathrm{Lwr}+/-}\right)$ have enlarged lateral ventricles and decreased dendritic spine density on subicular pyramidal neurons. Magnetic resonance imaging of type III Nrg1 heterozygous mice revealed hypofunction in the medial prefrontal cortex and the hippocampal CA1 and subiculum regions. Type III Nrg1 heterozygous mice also have impaired performance on delayed alternation memory tasks, and deficits in prepulse inhibition (PPI). Chronic nicotine treatment eliminated differences in PPI between type III Nrg1 heterozygous mice and their wild-type littermates. Our findings demonstrate a role of type III Nrg1 signaling in the maintenance of corticostriatal components and in the neural circuits involved in sensorimotor gating and short-term memory.
\end{abstract}

Key words: lateral ventricle; dendritic spine; cerebral blood volume; memory; prepulse inhibition; schizophrenia

\section{Introduction}

The Neuregulin-1 (Nrg1) gene encodes a family of signaling proteins mediating cell-cell interaction in the brain and other organs by signaling through erbB receptor tyrosine kinases (Buonanno and Fischbach, 2001; Falls, 2003). Functions of Nrg1 on the cellular and synaptic levels of the nervous system have been assessed

\footnotetext{
Received June 26, 2007; accepted May 7, 2008

This work was supported by National Institutes of Health Grants NS29071 and DA019941 (L.W.R., D.A.T.) and in part by funds from the Philip Morris External Research Program (L.W.R.). Additional support came from National Institute of Mental Health [Silvio Conte Center for the Neural Basis of Mental Disorders Grant P50 MH66171-01 (H.M.)], the Lieber Center for Schizophrenia Research at Columbia University (H.M.), and National Alliance for Research on Schizophrenia and Depression/Baer Distinguished Investigator Award (L.W.R.). Cognitive and behavioral experiments were conducted in the facilities of the Rodent Models Neurobehavioral Testing Core of the Liebe Center for Schizophrenia Research at Columbia University and the New York State Psychiatric Institute (H.M., Director). We thank D. Wolpowitz for initial in situ analyses and N. Mendell and C. Chen for statistical consultations; C. Schmauss and C. Kwon for help with memory-related behavior experiments; E. Johnson for help on the dendritic spine analyses; John Smiley for help in the anatomical studies; P. Flaubas, C. Hong, and D. Wiedl for technical support; and R. Hen, C. Schmauss, and M. Saxe for comments on the initial stage of this manuscript.

Correspondence should be addressed to either of the following: Dr. David A. Talmage at his present address: Department of Pharmacology and Center for Brain and Spinal Cord Research, Stony Brook University, Stony Brook, NY 11794-5230, E-mail: david.talmage@stonybrook.edu; or Dr. Lorna W. Role at her present address: Center for Brain and Spinal Cord Research, Stony Brook University, Stony Brook, NY 11794-5230, E-mail: lorna.role@stonybrook.edu.

Y.-J. J. Chen's present address: Nina Ireland Laboratory of Developmental Neurobiology, Department of Psychiatry, University of California at San Francisco, San Francisco, CA 94158.

R.-C. Liu's present address: Pfizer, Inc., La Jolla, CA 92121.

DOI:10.1523/JNEUROSCI.1815-08.2008
}

Copyright $\odot 2008$ Society for Neuroscience $\quad 0270-6474 / 08 / 286872-12 \$ 15.00 / 0$ by stimulating or interfering with $\mathrm{Nrg} 1 /$ erbB signaling. Addition of recombinant $\mathrm{Nrg} 1$ protein to neurons in vitro alters glutamatergic, GABAergic, and cholinergic synaptic transmission as well as inducing structural changes of hippocampal and cerebellar neurons (Ozaki et al., 1997; Yang et al., 1998; Rieff et al., 1999; Liu et al., 2001; Okada and Corfas, 2004; Gu et al., 2005; Kwon et al., 2005; Woo et al., 2007). Ablation of presynaptic Nrg1 or postsynaptic erbB signaling prevents cholinergic and glutamatergic synapse maturation and plasticity (Yang et al., 1998; Li et al., 2007). Genetic deletion of components of Nrg1/erbB signaling results in transformation of radial glial cells into astrocytes (Schmid et al., 2003), loss of interneurons or sensory and motor neurons (Wolpowitz et al., 2000; Bao et al., 2003; Flames et al., 2004), decreased myelination (Chen et al., 2003; Michailov et al., 2004; Taveggia et al., 2005; Roy et al., 2007), and aberrant axonal projections (Wolpowitz et al., 2000; Lopez-Bendito et al., 2006).

More than $15 \mathrm{Nrg} 1$ isoforms are generated from the $\mathrm{Nrg} 1$ gene through distinct promoter usage and alternative splicing (Falls, 2003; Steinthorsdottir et al., 2004). Different Nrg1 isoforms are expressed in disparate areas in the brain and play discrete, sometimes complementary, roles in neural development (Meyer et al., 1997; Anton et al., 2004; Flames et al., 2004; Michailov et al., 2004; Taveggia et al., 2005; Lopez-Bendito et al., 2006) (for review, see Falls, 2003). Highly expressed throughout embryonic and postnatal brain development (Meyer et al., 1997; Anton et al., 2004; Longart et al., 2004), type III Nrg1 isoforms interact with erbB 
receptors on neighboring neurons or glia in a juxtacrine manner (Wang et al., 2001; Falls, 2003; Taveggia et al., 2005). Moreover, juxtacrine signaling between type III Nrg1 and erbB receptors is bidirectional, mediating neuronal survival and activitydependent synaptic plasticity (Bao et al., 2003, 2004).

The importance of type III Nrg1 in the nervous system has been revealed by studies on isoform-specific knock-out mice. Complete loss of type III Nrgl expression leads to widespread failure to maintain peripheral synapses, degeneration of sensory and motor neurons, and defective neuronal and axonal migration in the telencephalon (Wolpowitz et al., 2000; Flames et al., 2004; Lopez-Bendito et al., 2006). Type III Nrg1 heterozygous mice have hypomyelination (Michailov et al., 2004; Taveggia et al., 2005). Studies using cells derived from type III Nrg1 mutant mice have also established the importance of these isoforms in neuronal survival, presynaptic targeting of $\alpha 7$-containing nicotinic acetylcholine receptors, and the establishment of certain glutamatergic synapses (Bao et al., 2003) (C. Zhong, M. Hancock, C. Du, S. Singer, M. Mertz, L. Role, and D. Talmage, unpublished observations). To further elucidate the physiological functions of type III Nrg1 in the development and maintenance of neural circuits of particular importance for schizophrenia, we assessed the regulation of type III Nrg1 expression and the effects of heterozygous disruption of the type III Nrg1 gene.

\section{Materials and Methods \\ Animals}

Type III Nrg1 heterozygous mutant mice $\left(\mathrm{Nrg} 1^{\mathrm{tm} 1.1 \mathrm{Lwr}}\right)$ and their wildtype littermates were generated by crossing heterozygotes, yielding a ratio of two heterozygotes and one wild type, because homozygous mutant mice die at postnatal day 0 (P0) (Wolpowitz et al., 2000). Heterozygous crossing has been practiced for $>20$ generations, resulting in animals with a homogeneous genetic background for most genes except for the type III Nrgl gene locus. Genotypes were determined by PCR as described previously (Wolpowitz et al., 2000). Animals were maintained on a $12 \mathrm{~h} \mathrm{light/dark} \mathrm{cycle} \mathrm{and} \mathrm{provided} \mathrm{with} \mathrm{food} \mathrm{and} \mathrm{water} \mathrm{ad} \mathrm{libitum.}$ Animal testing was conducted in accordance with the Principles of Laboratory Animal Care and the guidelines of the National Institutes of Health and the Institutional Animal Care and Use Committee.

\section{Rapid amplification of $5^{\prime}-c D N A$ end analysis}

Rapid amplification of 5' -cDNA end (5'-RACE) analysis was performed by following the manufacturer's instruction (Invitrogen). Total RNA was isolated from P0 mouse whole brain using TRIzol (Invitrogen) and RNeasy Mini kit (QIAGEN). Two micrograms of total RNA were reversed transcribed $\left(50 \mathrm{~min} ; 50^{\circ} \mathrm{C}\right)$ using gene-specific primer a. Firststrand cDNA was purified with S.N.A.P. column, and then the cDNA end was end-labeled with terminal transferase and dCTP. Gene-specific primer $\mathrm{b}$ was used in the first PCR amplification with abridged anchor primer (AAP), which recognized poly $(\mathrm{C})$ sequences of the cDNA tails. The PCR products were used as templates for nested PCR with genespecific primer $\mathrm{c}$ and abridged universal amplification primer (AUAP). Nested PCR products were purified and subcloned into the pBSSK (-) vector and inserts from four to approximately six clones were sequenced. Both AAP and AUAP are provided by the $5^{\prime}$-RACE kit. Sequences of each of the primers were as follows: primer a for exon 2, $5^{\prime}$-CTGCCTTCTTTGCGCTCAGA-3'; primer b for exon 2, 5' -GGTGTCTCGGGGCTACTCT-3'; primer $\mathrm{c}$ for exon $2,5^{\prime}$-cgggatccTTGGACGCAGGCGCTCCTCCTT-3'; primer a for exon 7, 5'-AAGGGCTTCTAGCAACTATG$3^{\prime}$; primer b for exon 7, 5'-CCAAACCATCCCGGTTGGTTCA-3'; primer $\mathrm{c}$ for exon 7, 5' -cgggatccGTATCCCAAACTGAAAGGCATGT$3^{\prime}$. The capital letters are sequences from exons, whereas the lowercase letters are sequences with BamHI site designed for cloning.

\section{In situ hybridization}

Mouse in situ probes for type III Nrg1 and ErbB4 were from 607 to 1206 nt of GenBank accession number AF045654 and 3088-3957 nt of acces- sion number L07868, respectively. In situ hybridization results were obtained using nonradioactive, digoxigenin (DIG)-UTP-labeled probes (sense and antisense) according to manufacturer's instructions (Roche). Mice (P3-P14) were fixed in 4\% paraformaldehyde by transcardial perfusion, and brains were removed and postfixed overnight at $4^{\circ} \mathrm{C}$. After cryoprotection in 30\% sucrose, brains were embedded in OCT, and 12 $\mu \mathrm{m}$ coronal sections were cut and collected on slides. Sections were treated with $4 \%$ paraformaldehyde for $20 \mathrm{~min}$ and washed in PBS. Then they were treated with acetic anhydride solution $\left(295 \mathrm{ml}\right.$ of $\mathrm{H}_{2} \mathrm{O}$ with 4 $\mathrm{ml}$ of triethanolamine, $0.525 \mathrm{ml}$ of concentrated $\mathrm{HCl}$, and $0.75 \mathrm{ml}$ of acetic anhydride) and washed with PBS. The sections were placed in a slide mailer containing prehybridization solution ( $50 \%$ formamide, $1 \times$ Denhardt's, 0.1\% Tween 20, $250 \mu \mathrm{g} / \mathrm{ml}$ Escherichia coli MRE 600 tRNA, $500 \mu \mathrm{g} / \mathrm{ml}$ herring sperm DNA) and incubated at room temperature for $2 \mathrm{~h}$. Hybridization was done at $70^{\circ} \mathrm{C}$ overnight with DIG-UTP-labeled RNA probes (sense or antisense) in the prehybridization solution at a concentration of $1 \mathrm{ng} / \mu \mathrm{l}$. The next day, the sections were washed at $70^{\circ} \mathrm{C}$ with $5 \times$ SSC for $10 \mathrm{~min}$ and $0.2 \times$ SSC for four times $(30 \mathrm{~min}$ each). Another $0.2 \times$ SSC wash at room temperature was followed by a TBS wash $(0.1 \mathrm{M}$ Tris, $\mathrm{pH} 7.5,0.15 \mathrm{M} \mathrm{NaCl})$. The sections were blocked with $10 \%$ sheep serum in TBS for $1 \mathrm{~h}$ at room temperature before incubating with an alkaline phosphatase-conjugated anti-DIG antibody (Roche; 1:4000; in TBS with $10 \%$ sheep serum and $0.1 \%$ Triton X-100) overnight at $4^{\circ} \mathrm{C}$. Sections were then washed with TBS containing $0.1 \%$ Triton X-100 three times for $45 \mathrm{~min}$ total. For the color development, sections were equilibrated with buffer containing $0.1 \mathrm{~m}$ Tris, pH 9.5, $0.1 \mathrm{M} \mathrm{NaCl}$, $50 \mathrm{~mm} \mathrm{MgCl}_{2}, 0.1 \%$ Triton X-100, and $0.24 \mathrm{mg} / \mathrm{ml}$ levamisole for $10 \mathrm{~min}$ before applying NBT/BCIP (nitroblue tetrazolium/5-bromo-4-chloro3-indolyl phosphate) (Roche; $20 \mu \mathrm{l} / \mathrm{ml}$ in the above buffer) and incubated at $37^{\circ} \mathrm{C}$ for $4-6 \mathrm{~h}$. After color development, sections were mounted and photographed without counterstaining.

\section{Lateral ventricle measurement}

Brains from wild-type and type III Nrg1 heterozygous sibling mice (agematched animals from P1, P22, 3 months, 6 months, 7 months, and 16 months) were fixed with $4 \%$ paraformaldehyde by transcardial perfusion and postfixed overnight at $4^{\circ} \mathrm{C}$. After cryoprotection in $30 \%$ sucrose for $24 \mathrm{~h}$, brains were embedded in OCT and serial coronal brain sections $(20$ $\mu \mathrm{m}$ thickness) were mounted on slides and stained with hematoxylin to reveal gross morphology. The parameters used to assess the regions of lateral ventricle areas measured include the following: (1) identification of three structural landmarks (genu of the corpus callosum, anterior commissure, and the fimbria of the hippocampus), (2) gross morphology of surrounding tissue, and (3) a minimum of five ( $400 \mu \mathrm{m}$ to $1 \mathrm{~mm}$ apart) serial sections per animal.

\section{Golgi impregnation and dendritic spine analysis}

Five wild-type and five heterozygous age-matched ( 6 months of age) littermate pairs were killed by exposure to $\mathrm{CO}_{2}$. The brains were removed and processed with a modification of the Golgi-Cox method (Glaser and Van der Loos, 1981). Sections were cut from Parlodion (nitrocellulose) blocks at a thickness of $200 \mu \mathrm{m}$.

Neurons in the inner pyramidal cell layer of the ventral subiculum were chosen for tracing by systematic random sampling. To ensure accurate analysis, we required that at least $150 \mu \mathrm{m}$ of length of the main shaft of the apical dendrite be included in the section, and we excluded neurons whose dendrites were obscured by stained bodies of other cells. One to six neurons were traced from each section containing the subiculum area, and at least four neurons were analyzed per animal.

Neurons were observed on an Axioplan2 microscope (Carl Zeiss) using a C-APOCHROMAT $63 \times$ water immersion objective (numerical aperture, 1.2). Real-time images were obtained by a digital video camera (Digital Video Camera Company) and cells were traced on a computer monitor by an observer, blind to genotype, using Neurolucida software (MBF Bioscience). For each cell traced, the software quantified dendritic structure. Concentric three-dimensional shells of increasing radius (in $10 \mu \mathrm{m}$ increments) were centered on the soma of the neuron. The numbers of spines, and total dendritic length between adjacent shells were determined separately for the apical dendrite and the combined basilar 
dendrites of each neuron. The spine density between adjacent shells was calculated by dividing spine numbers by dendritic length. The analyses for the apical dendrites were restricted from 0 to $380 \mu \mathrm{m}$ away from soma, because there are only a few neurons with apical dendrites longer than $350 \mu \mathrm{m}$. The average lengths are $\sim 325 \mu \mathrm{m}$ for both genotypes. After the analyses were completed, genotypes were unmasked. Effects of genotype were analyzed using nonparametric analyses [Kolmogorov-Smirnov tests (K-S tests)].

\section{In vivo imaging}

To assess cortical and hippocampal function with in vivo imaging, we used a high-resolution magnetic resonance imaging technique that estimates regional cerebral blood volume (CBV) (Moreno et al., 2006), a validated correlate of neuronal function (Small, 2003). Mice (six $+/+$ and nine $+/-; 6$ months of age) were imaged with a 9.4 T Bruker scanner (AVANCBV 400WB spectrometer; Bruker NMR) by following a previously described protocol (Pereira et al., 2007). Briefly, axial T2-weighted images were optimally acquired with a fast sequence (time to repeat/ effective echo time, 2000/70 ms; $30 \mathrm{~mm}$ inner diameter birdcage radio frequency probe; shielded gradient system, $100 \mathrm{~g} / \mathrm{cm}$; rapid acquisition with relaxation enhancement factor, 16; field of view, $19.6 \mathrm{~mm}$; acquisition matrix, $256 \times 256$; number of slices, 8 ; slice thickness, $0.6 \mathrm{~mm}$; slice gap, $0.1 \mathrm{~mm}$; number of excitations, 28). Four sets of images were acquired sequentially, each requiring $16 \mathrm{~min}$. The first set was precontrast. Gadodiamide was then injected $(13 \mathrm{mmol} / \mathrm{kg}$, i.p.) through a catheter placed intraperitoneally before imaging. The last three sets corresponded to the postcontrast images. To prevent head motion and reduce anxiety, the animals were anesthetized with isoflurane gas $[1.5 \%(\mathrm{v} / \mathrm{v})$ for maintenance at 1 liter per minute of air flow] via a nose cone. Monitoring of the heart rate, respiratory rate, and oxygen saturation was performed during the whole procedure. Relative CBV was mapped as changes of the transverse relaxation rate $\left(\Delta R^{2}\right)$ induced by the contrast agent. When the contrast agent reaches uniform distribution, CBV maps can be measured from steady-state T2-weighted images as CBV $\infty \Delta R^{2}=\ln \left(S_{\text {pre }} / S_{\text {post }}\right) /$ TE, where TE is the effective echo time, $S_{\text {pre }}$ is the signal before the contrast administration, and $S_{\text {post }}$ is the signal after the contrast agent reaches steady state. To control for differences in levels of contrast administration, cardiac output, and global blood flow, the derived maps were normalized to the maximum 4 pixel signal value of the posterior cerebral vein. Visualized anatomical landmarks were used together with standard atlases to identify the localization of regions of interest. Regions of interest included the five hippocampal subregions (dentate gyrus, the CA3 subfield, the CA1 subfield, subiculum, and the entorhinal cortex); the nucleus accumbens; the medial prefrontal cortex including medial orbital cortex, prelimbic cortex, and infralimbic cortex; and finally, lateral prefrontal cortex including sensory and motor cortex. The normalized CBV measurements [regional cerebral blood volume (rCBV)] from each subregion were used for group data analyses.

\section{Behavioral analyses}

Behavioral studies were conducted on either sibling male mice (5-7 months of age; T-maze) or age-matched male animals [3-8 months of age, prepulse inhibition (PPI) assay; $8-11$ months of age, PPI assay with nicotine administration] as described by Glickstein et al. (2002) and Stefansson et al. (2002). Mice were acclimated to the behavioral testing room for 1 week before the test.

Locomotor activity in a novel open field. For locomotor activity in a novel open field, each mouse was placed in a square open field box $(17 \times$ $17 \times 12$ inches) in a dark room for $30 \mathrm{~min}$ as described previously (Stefansson et al., 2002). Photocell beam measurements of open-field locomotion can evaluate total amount of movement, rate of movement, and type of spontaneous activity. Activity data were collected in $5 \mathrm{~min}$ intervals (bins) over the $30 \mathrm{~min}$ test period and were analyzed with ANOVA. Mice are age-matched wild-type and type III Nrg1 heterozygous mice (5-7 months).

Continuous delayed alternation test in a T-maze. For the continuous delayed alternation test in a T-maze, we adapted the method using an apparatus similar to that described previously (Glickstein et al., 2002). Animals were food deprived for 2 weeks until body weight reached $80 \%$ of initial value ( $2.5 \mathrm{~g}$ of food per animal per day). Daily feedings were subsequently adjusted so that each animal maintained body weight at $\sim 80 \%$ of the starting weight. For all experiments, the T-maze apparatus was located at the same position in a quiet room. All experiments were conducted between 2:00 and 4:00 P.M. (for training and short-delay periods) or 12:00 and 6:00 P.M. (for long-delay periods).

Training was as follows: Animals were introduced to T-maze with both arms baited with food (honey nut cereal) for 3 consecutive days, followed by $3 \mathrm{~d}$ of "forced alternation choice." In this phase, animals could enter either arm (both left and right arms were open and baited with food; "L/R choice") and eat for $12 \mathrm{~s}$ before they were replaced in the holding chamber. In subsequent trials (forced choice), animals were barred from entry of the arm just visited and open to the opposite (baited) arm of the T-maze, training the animals to alternate choices to obtain the reward. During the final training phase (2-3 weeks), each day began with one forced choice followed by 10 free-choice trials. In free-choice trials, both arms were open but only the arm opposite to the arm baited on the previous trial was baited. During training, there was a $7 \mathrm{~s}$ delay time between trials when the animals remained in the holding chamber. If the animals made the wrong choice (i.e., entered the arm visited in the previous trial), they would be kept in the arm for $12 \mathrm{~s}$ before being placed back to the holding chamber. In this case, the baited arm for the next trial would not be changed (i.e., the bait remained in the opposite arm). Because wild-type and type III Nrg1 heterozygous animals did not differ in their acquisition of the rule, the training session ended when the average percentage of correct trials of all animals reached $80 \%$ on 3 consecutive days.

In the first series of tests, nine wild-type and nine type III Nrg1 heterozygous littermates (4 months of age at the start of testing) were subjected to one delay for all trials within a day, and with the following delays used on successive test days: 15, 20,30, 45, 60, and 120 s. On each day, the animals were tested at the indicated delay time for 10 continuous trials. For the 15 and 60 s delay shown in Figure 6, $A$ and $B$, we used $2 \mathrm{~d}$ averages of the first five trials for individual animals. In the second series, 9 wildtype and 13 type III Nrg1 heterozygous littermates (6-7 months at the start of testing) were subjected to a mixture of different delay periods across 12 continuous trials each day. The animals were acclimated to the mixed-delay paradigm with six trials of $5 \mathrm{~s}$ delay and six trials of $15 \mathrm{~s}$ delay (in a sequence of 15-15-5-5 for three times). Animals were next tested with four trials of $15 \mathrm{~s}$ delay, four trials of $30 \mathrm{~s}$ delay, and four trials of $60 \mathrm{~s}$ delay (in a sequence of 60-15-30 for four times). Two day averages of performance were obtained for individual animals at $15 \mathrm{~s}$ delay and at $60 \mathrm{~s}$ delay from the 60-15-30 mixed-delay tests as shown in Figure 6, A and $B$.

Prepulse inhibition. For PPI, mice were placed in acoustically isolated startle chambers (MED Associates). The test started with a $10 \mathrm{~min}$ acclimation followed by three sessions of trials. Background noise was $70 \mathrm{~dB}$ throughout the acclimation and trial periods. Sessions 1 and 3 included 10 trials of startle stimuli ( $120 \mathrm{~dB} ; 40 \mathrm{~ms})$. Session 2 consisted of 56 trials in which startle response magnitude (the area under curve), peak latency, and onset latency to each stimulus were obtained for trials in which the startle stimulus was presented alone or preceded by $100 \mathrm{~ms}$ with a $15 \mathrm{~ms}$ prepulse. The prepulse amplitude was 2,4 , or $8 \mathrm{~dB}$ above background (Stefansson et al., 2002). The startle response was defined as changes in force on the floor (i.e., "displacement") between 30 and $70 \mathrm{~ms}$ after the onset of the startle stimulus. Animals failing to emit a reliable baseline startle response of at least 100 arbitrary units were excluded (Stefansson et al., 2002), resulting in an exclusion of approximately one-third of both WTs and Nrg 1 type III heterozygotes. PPI was calculated as $1-(\operatorname{ppr}[x] /$ $\operatorname{sr})$, where $\operatorname{ppr}[x]$ is the average startle response across trials presenting a prepulse of amplitude $x$, and sr is the average startle response across trials in which the startle stimulus was presented alone. Data were analyzed by mixed-model repeated-measures ANOVA with genotype as an independent variable and prepulse amplitude as the repeated measure.

Nicotine treatment paradigm. We began nicotine administration 6 weeks after initial PPI testing (mice were $8-11$ months of age) by inclusion in the drinking water of $(-)$-nicotine and $2 \%$ sucrose. The concentrations of nicotine were stepped up progressively from 25 to $100 \mu \mathrm{g} / \mathrm{ml}$ 


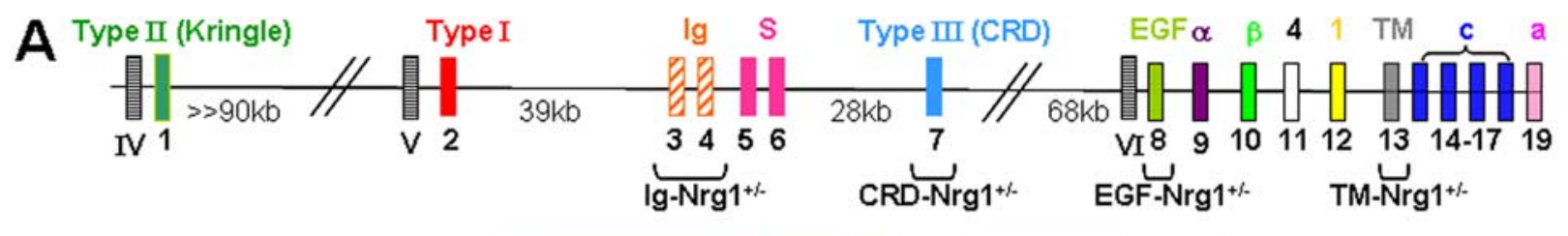

\section{Type I Nrg1}

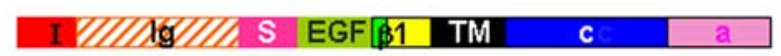

\section{Type II Nrg1}

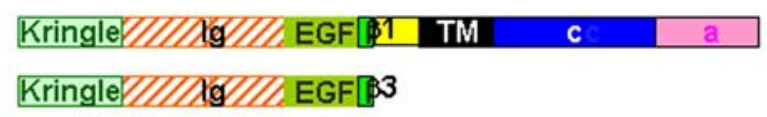

\section{Type III Nrg1}

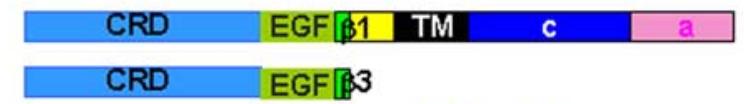

Exon 7 (Type III)

\section{Exon 2 (Type I)}

GACCCCTGTC GGGAGTTCCC GGCAGCCGCT GGGCTCCGCC GCCDCTAGGC TGGCCCAGCT GCCAGAAGA AGGGGCTGAG CCGTGATCGC CAAACTCAGG CTCCTCCCGG TGGCGTGTCT GCGCCTCGGG GTGGGGGTGT GGTGGGGAA GAGGGAGGGG GCGAGGCGAG GGGAGGGTGC GHQGGAGGCG_CCTGCITCCAI ACCTGCGGGC AATTGAAAA GAGCCGGCTA GGACTTCCCC AAAACTTGTG GGAACTCCGG GCCGCGCCGG CAGCAGGAGC GGAACGCAGC GCAGCGGCGG CAGCTGCCGG GAGATGCGAG CATAGACCGG ACTGTGAGCA CCTTTCCCTC TTCGGGCTGT AAGGGAGCGA GACAGCCACC GGAGCGAGGC CACTCCAGAG CCGGCAGCGG CAGGACCCGG GACACAAGG-TAGCCCCGAG ICACECCCAGIACGTAGCGGG CGCTCCAGGT GATCGAGTCC ACGCCGCTCC CTGCAGGCGA CAGGCGACGC CCCCGCGCAG CCCGGCCGCT GGCTCTTCCC TCCCGGGATC AAACTTTTCT GCAAGCCCTT GGACCAAACT TGTCGCGCGT CACCGTCGCC CAGCCGGGTC CGCGTAGAGC GCTCATCTTT AGCGAGATGT GTGAGGGGAIAGAAGGCAGA GGCAAGGGGA AGGGCAAGAA GAAGGACCGG GGATCCCGCG GGAAGCCGC GCCCGCCGA GGCGACCCGA GCCCAGGTGA GTGCCAGCCG

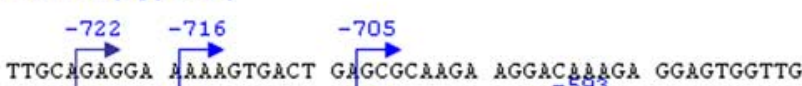

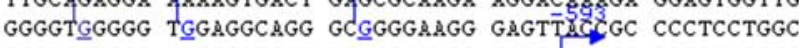
TCCTCCTGCC CTCGCATCCT TGTGCAATGG TACTCTTTGC CGTGATGCTC AGAGGGCAGG CACCTGCTGC TCTGTAATGA TTCAGCCTCT TTCAGCCGCT GCGTTAACAC GACAGGATGC TGTTGCTACT GTCGCTGCTG CCCCTCCTGC CGCCGCCGCT GCTGCCGCCG CCGCCTCCTC TGGTCTTGCT TTTGCTTTTA CTTCTCCTGC ATGACAGTTG TTTTCTTCCT CTAAGCAGAC ACCAGCTTCA GACGCTTGAG GTGAGAAA A IGCCITICAG ITTGGGISAC TGGTTTACTTCRD-C AATCAGCTAG GCATCAGCTT GCTTCCTCTT TTGGTCCCCT GCCTTCTTGA ACCAACCGGG ATGGTTTGGA GAACCTTTG AAAAACTGA AAAGTGTCC CAGAAACAAC AGCTCAAGAT ATTTCGGTAC ACTTCTATTT ALAGTIGCTCRD-b \&GABGCCTT TCTTTTTCGT TTCTTTTTCT TTTTTTTTTT TCTTTTTTTT a TTTTTTTTTT TTTTTATCTT TTTCTTGCTT CEICIIMGC ICTCTIACITCRD-a IGGATAATGG_CETTGGACTT GGGTGCCTTA TCGATTTCCC CCTTCAAGAT GCTGTATCAT TTGGTTGGGG GGAGCTCTGC ATGGTAATGC ACTGTGAGAG AGGCCGGGCC TTCTGGAGGT GATCCGGATG GAGATTTATC CCCCAGACAT GTCTGAGGGA GCTGGCGGGA GGTCCTCCAG CCCCTCCACT CAGCTGAGTG CAGACCCATC TCTCGATGGG CTTCCGGCAG CGGAACATAT GCCAGACACC

Figure 1. Neuregulin 1 gene and protein structures and the transcriptional start sites for type I and type III Nrg1 isoforms. A, The Nrg1 gene structure on mouse chromosome 8 (top) and the domain organization of three major types of $\mathrm{Nrg} 1$ proteins (bottom). Top, The colored blocks indicate individual exons. The approximate sizes of the introns are also indicated (not drawn to scale). All Nrg1 proteins share the EGF-like domain necessary for binding ErbB receptors. Each major type of Nrg1 protein is encoded by a distinct N-terminal exon: exon 2 (type I), exon 1 (type II), and exon 7 (type III), respectively. Three additional 5' exons found in humans that encode type IV, V, and VI are shown as hatched boxes. C-terminal to the EGF domain, Nrg1 proteins either exist as soluble $(\beta 3)$ or transmembrane proteins (the $\beta 1$ a variant is depicted). Nrg1 heterozygous mutant mice that are described in supplemental Table 2 (available at www.jneurosci.org as supplemental material) are labeled to indicate regions (isoforms) that are disrupted in each mutant mouse. S, Spacer; (RD, cysteine-rich domain; EGF, EGF-like domain; TM, transmembrane domain. $\boldsymbol{B}$, Transcriptional start sites for type I and type III Nrg1 mRNA were identified by sequencing multiple PCR products amplified using a standard 5'-RACE protocol. The identified 5' ends of type I (left) and type III (right) transcripts are underlined and colored (red and blue, respectively). All type I products originated at nucleotide -542 relative to the translational initiation codon in exon 2 (bold ATG). Four distinct $5^{\prime}$ ends for type III transcripts were identified 593,705, 716, and 722 nt 5' to the first coding ATG in exon 7 (the black letters indicate noncoding sequences, and the colored letters indicate coding sequences). The dashed lines with arrows pointing the orientation indicate primers (I-a, -b, -c; CRD-a, -b, -c) used in 5'-RACE (see Materials and Methods). The sequence information is extracted from Celera locus cra_cmgc_G 307972 BP.

at the first week, and then maintained at $200 \mu \mathrm{g} / \mathrm{ml}$ until retesting in PPI assay (6 weeks later).

\section{Statistical analysis}

Data obtained from some of the morphological analyses and behavioral experiments were distributed with multimodal and/or skewed normal profiles (as assessed by Tukey's stem and leaf). Such data were analyzed using mixed-model and/or nonparametric (Kolmogorov-Smirnov) analyses to test for statistical significance. The data of lateral ventricle volume were subjected to log-linear transformation followed by ANOVAs. All other data were subjected to standard ANOVAs followed by the use of Tukey's post hoc comparisons or Student's $t$ tests for planned comparisons. The results of power analyses for each ANOVA are reported in the supplemental material (available at www.jneurosci.org). Data were analyzed with StatView Software (SAS Institute) or SPSS. The power for each of the ANOVA analyses is as follows: genotype as an independent variable: lateral ventricle (LV), 0.69; functional brain imaging, 0.97 [subiculum (SUB)], 0.78 (CA1), 0.73 [medial prefrontal cortex (mPFC)], 0.57 (CA3); locomotor activity, 0.15; startle response, 0.11; PPI, 0.59. For the nicotine effects on PPI, the power is 0.19 (treatment as an independent variable), 0.32 (genotype), and 0.57 (between treatment by genotype).

\section{Results}

\section{Promoter analysis of Nrg1 and type III Nrg1 mRNA} expression in the perinatal brain

The Nrg1 gene encodes three major groups of isoforms that are defined by their first coding exon (Fig. 1A) (Falls, 2003). Type I $\mathrm{Nrg} 1$ and type II Nrg1 both contain an Ig domain N-terminal to the EGF domain, whereas type III Nrg1 contains a cysteine-rich domain N-terminal to the EGF-like domain. Genetic and cell biological studies reveal that different $\mathrm{Nrg} 1$ isoforms play discrete and sometimes complementary roles in neural development (Meyer et al., 1997; Wolpowitz et al., 2000; Falls, 2003; Flames et al., 2004; Michailov et al., 2004; Taveggia et al., 2005; LopezBendito et al., 2006). Generation of multiple isoforms of Nrg1 likely results from a combination of differential promoter usage and alternative splicing (Falls, 2003). To investigate the molecu- 


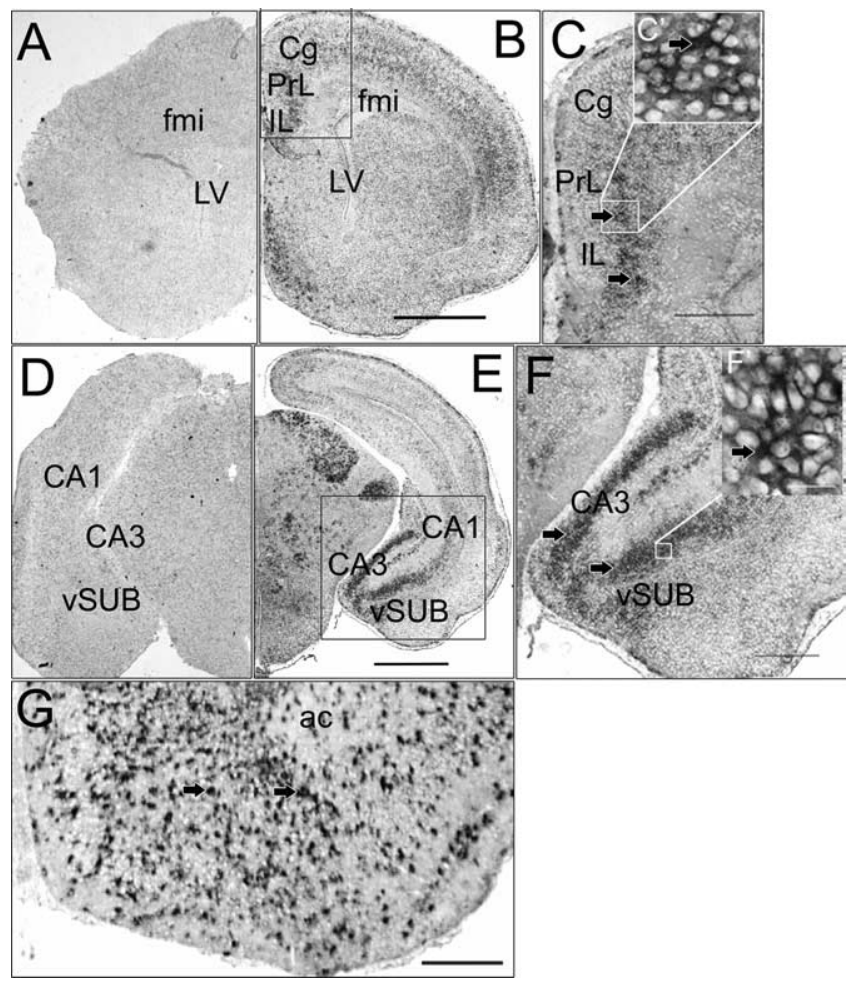

Figure 2. Expression of type III Nrg1 in the brain. In situ hybridization with a sense $(\boldsymbol{A}, \boldsymbol{D})$ or an antisense RNA probe $(\boldsymbol{B}, \boldsymbol{C}, \boldsymbol{E}, \boldsymbol{F})$ specific for type III Nrg1 revealed prominent expression (arrowheads) in corticolimbic regions of perinatal mouse brains including the following: the medial prefrontal cortex, anterior cingulate $(\mathrm{Cg})$, prelimbic cortex (PrL), infralimbic cortex (IL), and forcepts minor of corpus callosum (fmi) $\left(\boldsymbol{B}, \boldsymbol{C}, \boldsymbol{C}^{\prime}\right)$; hippocampal formation, particularly $\mathrm{CA}$ and ventral subiculum (vSUB) $\left(\boldsymbol{E}, \boldsymbol{F}, \boldsymbol{F}^{\prime}\right)$. $\boldsymbol{C}$ and $\boldsymbol{F}$ are enlarged views of the boxes delineated in $\boldsymbol{B}$ and $\boldsymbol{E}$. The insets $\left(\boldsymbol{C}^{\prime}, \boldsymbol{F}^{\prime}\right)$ in $\boldsymbol{C}$ and $\boldsymbol{F}$ are enlarged views of areas delineated by white boxes. $\boldsymbol{G}$, ErbB4 mRNA is expressed throughout the ventral striatum, which receives type III Nrg1-positive projections from $P F C$ and ventral hippocampus. ac, Anterior commissure. Scale bars: $\boldsymbol{B}$ (for $\boldsymbol{A}, \boldsymbol{B}$ ), $\boldsymbol{E}($ for $\boldsymbol{D}, \boldsymbol{E}), 800 \mu \mathrm{m} ; \boldsymbol{C}, \boldsymbol{F}, \mathbf{G}, 200 \mu \mathrm{m} ; \boldsymbol{C}^{\prime}, \boldsymbol{F}^{\prime}, 20 \mu \mathrm{m}$.

lar mechanisms regulating the expression patterns of type IIIversus type I-containing Nrg1 isoforms, we asked whether distinct promoters control Nrg1 transcription. 5'-RACE identified multiple transcriptional start sites continuous with, and within 1 $\mathrm{kb}$ of the type III Nrg1 coding region (Fig. $1 B$ ), indicating that a unique type III Nrgl core promoter lies immediately adjacent to the first exon of type III Nrg1.

The importance of type III Nrg1 in the nervous system is supported by studies of isoform-specific knock-out mice (Wolpowitz et al., 2000; Bao et al., 2003; Flames et al., 2004; Michailov et al., 2004; Taveggia et al., 2005; Lopez-Bendito et al., 2006). To investigate roles of type III Nrg1 in postnatal brain development, we examined RNA expression of type III Nrg1 and one of its receptors, ErbB4 in mice. Type III Nrg1 mRNA is expressed in medial prefrontal cortex and hippocampus (Fig. $2 B, C, E, F$ ), areas associated with attention, executive function, and memory (Naber et al., 2000; Vinogradova, 2001; Dalley et al., 2004). In the medial prefrontal cortex, type III Nrg1 is highly expressed in layer 5 in the cingulate cortex, prelimbic, and infralimbic cortices (Fig. $2 B, C)$. In the hippocampus, type III Nrg1 is predominantly seen in the CA3 and the subiculum (Fig. $2 E, F$ ). Fewer cells are positive for type III Nrg1 mRNA in the CA1 region, although the strength of expression is high (Fig. 2E). ErbB4 expression is detected in projection fields of the prefrontal cortex and ventral hippocampus, including the ventral striatum (Fig. 2G). As such, Nrg1/ ErbB4 signaling might be required for the maintenance of normal cortical and hippocampal structures and may influence corticolimbic circuits and related behaviors.

\section{Decreased type III Nrg1 results in enlarged lateral ventricles and decreased dendritic spine density on subicular neurons} To investigate the possible role of type III Nrg1 in adult brain organization and in the performance of specific behaviors, we compared adult type III Nrg1 heterozygous mutant mice $(+/-)$ with wild-type $(+/+)$ siblings [the homozygous mutants die at birth (Wolpowitz et al., 2000)]. Examining overall anterior brain morphology in coronal sections from $+/+$ and $+/-$ sibling pairs revealed enlarged lateral ventricles in $+/-$ animals. Serial sections were aligned by major landmarks [e.g., genu of the corpus callosum (cc); anterior commissure (ac)] (Fig. 3A) to permit comparisons between genotypes of the area indicated in Figure $3 A$. Starting with sections at the most anterior limb of the corpus callosum (section S1) to sections including the hippocampal formation (section S10), the lateral ventricular volume of $+/-$ mice ranged from 1.2 to 25 times larger than in comparable sections from $+/+$ littermates (Fig. $3 B, C$ ). Analysis of age-matched animals revealed statistically significant differences in total $L V$ volume between $+/+$ and $+/-$ animals (Fig. $3 D)(n=13+/+$ vs 18 $+/-; p<0.02)$. Thus, reduced type III Nrg1 signaling has a significant effect on gross morphology of adult brains, an effect that is more pronounced in older animals (Fig. 3D).

$\mathrm{Nrg1/ErbB}$ signaling contributes to synaptic plasticity and maturation at glutamatergic synapses (Bao et al., 2004; Li et al., 2007). Acute treatment with Nrg1 protein induces neurite outgrowth, extension, and branching in hippocampal neurons in vitro (Gerecke et al., 2004). Knockdown of ErbB4 with RNA interference in CA1 pyramidal neurons leads to decreased dendritic spine density in the CA1 pyramidal neurons (Li et al., 2007). The abundant expression of type III Nrg1 in the subicular region suggests a possible role in the synaptic plasticity of pyramidal neurons, in which proper dendritic arborization and spine density are required for accurate integration and processing of the convergent information from the hippocampus and extrahippocampal inputs. To analyze the dendritic spine density of subicular pyramidal neurons, brains from five pairs of $+/+$ and type III Nrg1 +/ - sibling mice were processed with modified Golgi methods (see Materials and Methods). We focused our analysis on coronal sections containing the ventral subiculum, where type III Nrg1 is highly expressed (Fig. 4A). The entire dendritic field (branches and spines on the apical dendrites and basilar dendrites) of individual, randomly chosen pyramidal neurons $(n=$ 30 neurons for $+/+; n=44$ neurons for $+/-$ ) from the inner layer of the subiculum were traced and analyzed. Two representative tracings of $+/+$ and $+/-$ neurons are shown in Figure $4 B$. Compared with their $+/+$ littermates, type III Nrg1 $+/-$ mice have significantly lower spine densities within the proximal apical dendrites of the pyramidal neurons $(\sim 50-210 \mu \mathrm{m}$ from the center of the soma) (Fig. 4C,D). Nonparametric Kolmogorov-Smirnov test using genotype as an independent variable and averaged apical spine density as an dependent variable revealed significant difference between genotype $\left(\chi^{2}=48.9 ; p_{\text {genotype }}<0.0001\right)$. The difference in spine density was significant along multiple $10 \mu \mathrm{m}$ bins (K-S test: $p<0.05$ at $50,80,140,180,190,200$, and $270 ; p<$ 0.01 at $70,100,150,170$, and 230) (Fig. $4 D$ ). Similarly, the spine density on the basilar dendrites of pyramidal neurons was lower from 40 to $100 \mu \mathrm{m}$ away from the soma in type III Nrg1 +/than in $+/+$ mice, although none of the $10 \mu \mathrm{m}$ bins reached statistical significance (data not shown). There were no statisti- 


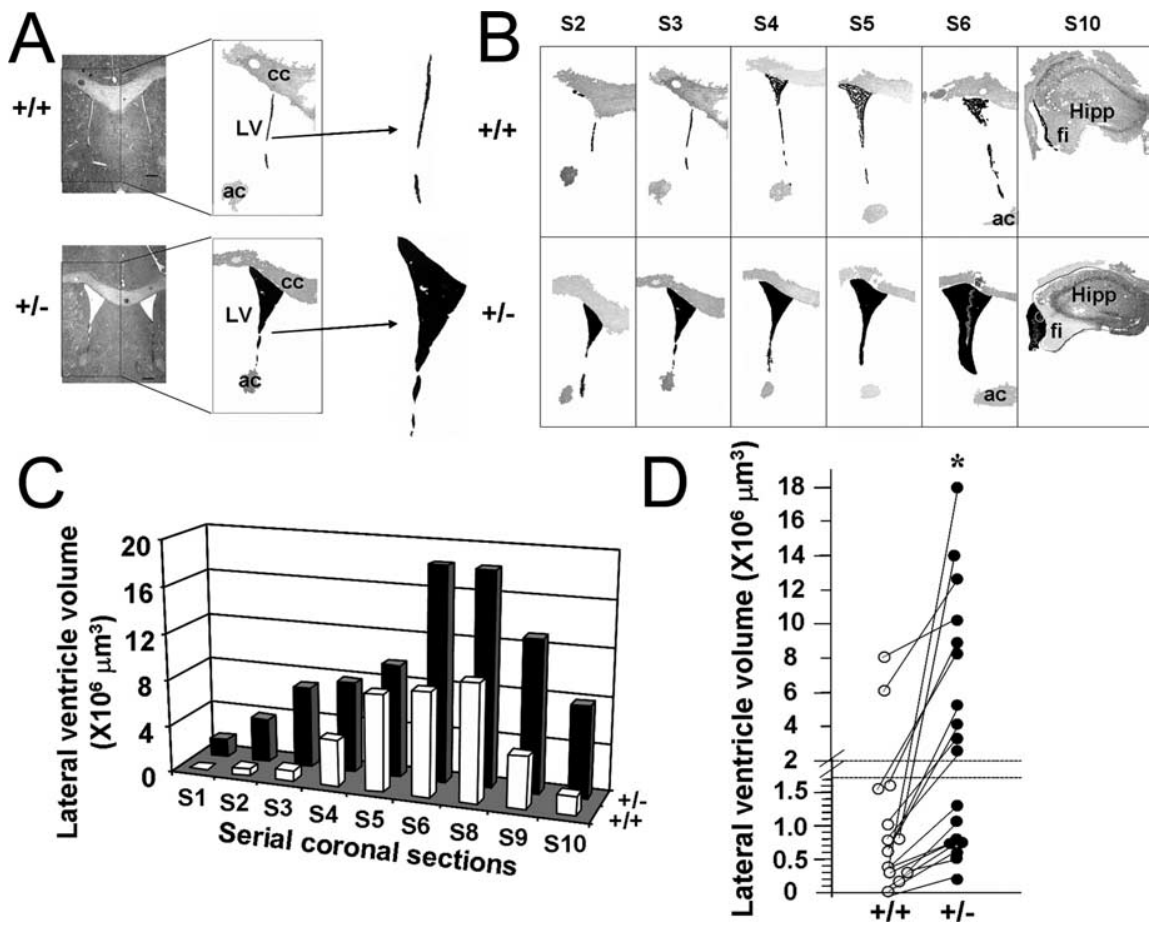

Figure 3. Enlarged lateral ventricles in type III Nrg1 heterozygous mice. $\boldsymbol{A}$, Diagram of coronal brain section, landmarks, and areas of lateral ventricle measured from wild-type $(+/+)$ and type III Nrg1 heterozygous $(+/-)$ sibling pairs. Scale bar: 300 $\mu \mathrm{m}$. cc, Corpus callosum; LV, lateral ventricle; ac, anterior commissure. $B, C$, Representative results obtained from adult sibling pairs previously tested in T-maze and prepulse inhibition assays (Figs. 7, 8A). $\boldsymbol{B}$, Hemisections from representative anterior regions measured. Top, Wild type $(+/+)$; bottom, heterozygote $(+/-)$. Hipp, Hippocampus; fi, fimbria. C, LV volume (in cubic micrometers) calculated from serial coronal sections and plotted from most anterior (S1) to posterior (S10) regions of wild-type $(\square)$ versus heterozygous ( $\square$ ) mice. D, Plot of LV volume (at level of S3) from 13 wild-type and 18 heterozygous mice (agematched $+1+$ and $+1-$ cases are connected with lines). Note that $y$-axis is discontinuous. There was a statistically significant difference of $L V$ volume between wild-type and heterozygous animals (ANOVA for $L V$ volume after log transformation, $F_{(1,29)}=$ $\left.6.37, p_{\text {genotype }}<0.02\right){ }^{*} p<0.05$.

cally significant differences in dendritic intersections or dendritic lengths between genotypes (data not shown).

Decreased type III Nrg1 leads to hypofunction in subregions of the hippocampus and the medial prefrontal cortex

Dendritic spines are the sites of most excitatory synaptic inputs and are known to be formed or eliminated in response to sensory experiences and neural activities (Engert and Bonhoeffer, 1999; Zuo et al., 2005; Holtmaat et al., 2006; Sheng and Hoogenraad, 2007). To determine whether structural alterations in hippocampal pyramidal neurons are translated into functional alterations, we compared rCBV, an indicator of brain metabolism and neuronal function (Gonzalez et al., 1995; van Zijl et al., 1998; Small, 2003), of type III Nrg1 $+/-$ mice versus $+/+$ controls $(n=6$ $+/+$ vs $9+/-$ ) (Fig. $5 A-D$ ). Compared with $+/+$ littermates, type III Nrg1 +/- mice have significantly lower rCBV in CA3, CA1, and the subiculum of the hippocampus (Fig. $5 B, C$ ) (differences between genotype using ANOVA test: SUB, $F=16.2, p<$ 0.002; CA1, $F=8.5, p<0.02$; CA3, $F=5.4, p<0.04)$. The functional activity of the dentate gyrus and the entorhinal cortex, major input pathways to the hippocampal trisynaptic circuit, were not significantly different between genotypes (Fig. $5 B, C$ ) (differences between genotype using ANOVA test: entorhinal cortex, $F=1.7, p=0.21$; DG, $F=2.4, p=0.15)$. Medial prefrontal cortex (medial orbital cortex, prelimbic cortex, and a fraction of the infralimbic cortex) as well as the ventral striatum (nucleus accumbens) receive inputs from CA1 and the subicu- lum (Groenewegen et al., 1987; Jay and Witter, 1991; Aylward and Totterdell, 1993; Barbas and Blatt, 1995; Carmichael and Price, 1995). Assessment of rCBV in $+/+$ versus $+/-$ mice revealed significantly lower $\mathrm{rCBV}$ in the medial prefrontal cortex (ANOVA test: $F=7.61, p<0.02$ ), but not in the nucleus accumbens of $+/+$ controls (Fig. 5C) (ANOVA test: mPFC, $F=7.61, p<0.02$; nucleus accumbens, $F=0.5, p=0.49)$. There were no significant differences between $+/+$ and $+/-$ mice in $\mathrm{rCBV}$ of the lateral frontal cortex (sensory/motor cortex) (Fig. 5C) (ANOVA test: $F=2.8, p=0.12)$. Calculation of the Pearson's correlation coefficient showed a significant positive correlation between rCBV in the medial prefrontal cortex and in the subiculum (Fig. 5D) (the Pearson's correlation coefficient is $0.743 ; p=0.002$; $R^{2}=0.552$ ).

\section{Decreased type III Nrg1 results in impaired performance in short-term memory tasks and deficits in sensorimotor gating}

The expression of type III Nrg1 in cortical areas, the anatomical phenotypes, as well as the decreased function in these regions led us to ask whether behaviors subserved by these regions are altered in type III Nrg1 heterozygous animals.

We first examined general activities of $+/-$ animals in a novel open field. During a period of $30 \mathrm{~min},+/+$ and $+/-$ animals $(n=17+/+$ and $21+/-)$ exhibited equivalent locomotor activities in the novel open field (Fig. 6). Total distances traveled were computed every $5 \mathrm{~min}$, and the total numbers of rears, jumps, and repetitive behaviors were recorded (Fig. $6 A, B$ ). There was no significant difference between $+/+$ and $+/-$ animals.

In rodents, a delayed alternation task in a T-maze tests shortterm and working memory and is sensitive to disruption of prefrontal cortical (PFC) and/or ventral hippocampal connectivity (Masuda et al., 1992; Shaw and Aggleton, 1993; Beracochea and Jaffard, 1995; Verma and Moghaddam, 1996; Glickstein et al., 2002; Le Marec et al., 2002; Lipska et al., 2002). The role of type III Nrg1 in short-term and working memory function was assessed by comparing $+/+(n=18)$ and type III $\operatorname{Nrg} 1+/-(n=22)$ male siblings in a continuous, delayed-alternation T-maze task (Glickstein et al., 2002). The memory load of this task is increased by imposing increasing delay times between trials. The ability of the mice to initially learn the rule of the task was not significantly affected by type III Nrg1 genotype (data not shown), nor were differences seen after small increases of the delay time between trials from $5 \mathrm{~s}$ (training interval) to $15 \mathrm{~s}$ (Fig. 7A). Although $+/+$ animals sustained their performance with delays up to $60 \mathrm{~s}$, as reported by others (Masuda et al., 1992; Beracochea and Jaffard, 1995; Jentsch et al., 1997; Kitabatake et al., 2003), the performance of type III Nrg1 +/ - mice deteriorated precipitously (Fig. $7 B)(p<0.008)$. Quantification of the change in performance between the short- and the long-delay period for each animal tested underscored the selective effect of increased delay time on 

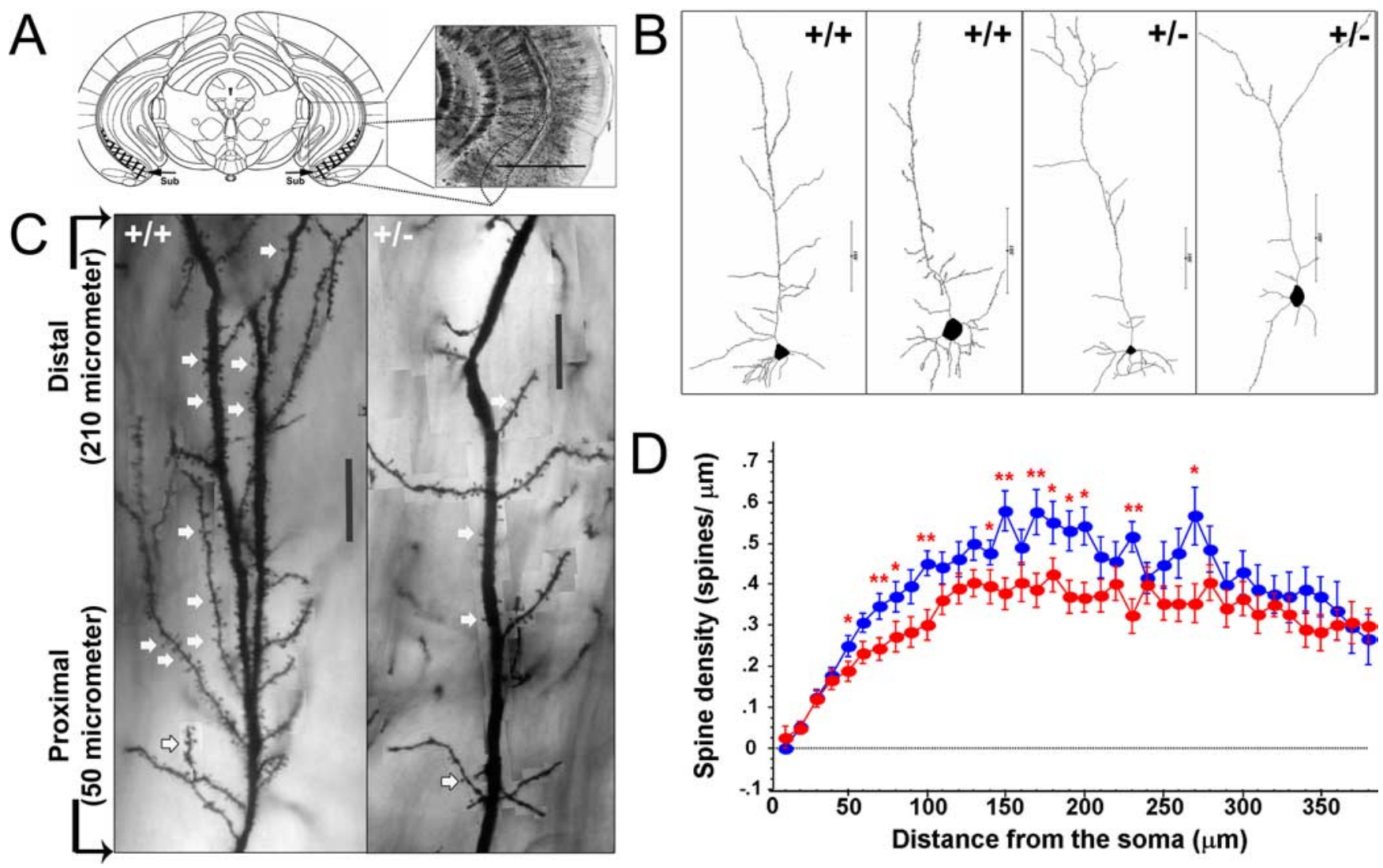

Figure 4. Type III Nrg1 heterozygous mice have decreased spine densities within proximal regions of apical dendrites of hippocampal pyramidal neurons compared with that of wild-type littermates. $A$, Diagram of a section (bregma, 3.40-3.64) containing the ventral subiculum (diagonal crossed lines) and a representative coronal section (Golgi stain) from which the pyramidal neurons were chosen (dashed line) and analyzed. Scale bar, $800 \mu \mathrm{m}$. B. Two wild-type neurons $(+/+)$ and two heterozygous neurons $(+/-)$ traced by Neurolucida program and reconstructed as three-dimensional structures are shown here as two-dimensional. Scale bar, $100 \mu \mathrm{m}$. C, Montages of photomicrographs of apical dendrites of a pyramidal neuron from $+/+$ or $+/-$ animal. The proximal and distal parts of the apical dendrites are indicated (shown here are dendrites 50 210 $\mu \mathrm{m}$ away from the center of the cell body). There are many more spines (examples indicated by white arrows) on dendrites from $+/+$ than from $+/-$ mice. Scale bar, $10 \mu \mathrm{m}$. D, Spine densities were plotted against increasing shell radius from the center of the soma. The results are from 30 neurons of five $+/+$ (shown in blue) and 44 neurons of five $+/-$ (shown in red) animals. Heterozygous mice have significantly lower spine densities at the $50-200$ shell radius compared with $+/+$ animals (nonparametric Kolmogorov-Smirnov test; ${ }^{*} p_{\text {genotype }}<0.05$ and ${ }^{* *} p_{\text {genotype }}<0.01$, respectively). Error bars indicate SEM.

the performance of heterozygous mice (Fig. 7C) (difference of performance at 15 and $60 \mathrm{~s}, p<0.003$ for $+/-)$.

PPI is an operational measure of sensorimotor gating (Braff et al., 2001), the process by which a weak sensory event can inhibit ("gate") the motor response to a very salient sensory event. The most common paradigm is the inhibition of the startle reflex of a loud tone by the presentation of a barely audible tone (the prepulse) just before the loud tone. Lesions and local pharmacological studies have shown that PPI is regulated by limbic temporal cortical inputs to the ventral striatum (Geyer et al., 2001; Swerdlow et al., 2005). To probe the importance of type III Nrg1 in these circuits, we assessed baseline acoustic startle and auditory PPI in adult $+/+(n=30)$ and $+/-(n=51)$ sibling animals. In the absence of a prepulse stimulus, there was no significant difference of the startle response amplitude between $+/+$ and type III Nrg1 $+/-$ mice (ANOVA using genotype as an independent variable, $\left.F_{(1,79)}=0.03, p_{\text {genotype }}=0.87\right)$. A mixed ANOVA (repeated measure $=$ prepulse level) showed a main effect of prepulse intensity $\left(F_{(2,158)}=29.03 ; p<0.0001\right)$. As shown in supplemental Table 1 (available at www.jneurosci.org as supplemental material), PPI increased with prepulse loudness. The analysis also revealed a main effect of genotype. Type III $\mathrm{Nrg} 1+/-$ mice had significantly less PPI than their $+/+$ littermates (Fig. $8 A$ ) (ANOVA, $F_{(1,79)}=4.93$, $\left.p_{\text {genotype }}<0.03\right)$. There was no significant interaction between prepulse intensity and genotype (two-way ANOVA, $F_{(2,158)}=0.33, p=0.72$ ).

Type III Nrg1 is important for the generation and maintenance of cholinergic neurons (Wolpowitz et al., 2000). Cholinergic modulation is important for integrating cortical information processing in the sensorimotor gating circuits (Liu et al., 2001; Ma et al., 2004; Sarter et al., 2005). Thus, baseline PPI was measured in a new group of mice (six of each genotype; 8-11 months of age) that were then administered nicotine (200 $\mu \mathrm{g} / \mathrm{ml}$ added to drinking water) for 6 weeks after which PPI was measured again (Fig. 8B). A mixed ANOVA showed that, although neither the main effect of genotype $\left(F_{(1,10)}=2.8 ; p=0.12\right)$ nor nicotine treatment $\left(F_{(1,10)}=1.5 ; p=\right.$ 0.24 ) was significant, there was a significant interaction of genotype and nicotine treatment $\left(F_{\text {interaction }(1,10)}=5.6 ; p<0.04\right)$. Post hoc pairwise comparisons using the Tukey method revealed that before nicotine, $-/+$ mice showed significantly lower PPI than $+/+\left(p_{\text {cor- }}\right.$ rected $<0.05)$, but after nicotine treatment there was no effect of genotype ( $p>0.7)$. Consistent with this, the orthogonal comparison showed that nicotine significantly increased PPI in heterozygotes $\left(p_{\text {corrected }}<0.05\right)$ but not in wild-type mice $(p>0.9)$.

\section{Discussion}

In the current study, we showed that (1) expression of type III and type I Nrg1 are controlled by distinct promoters; (2) type III Nrg1 

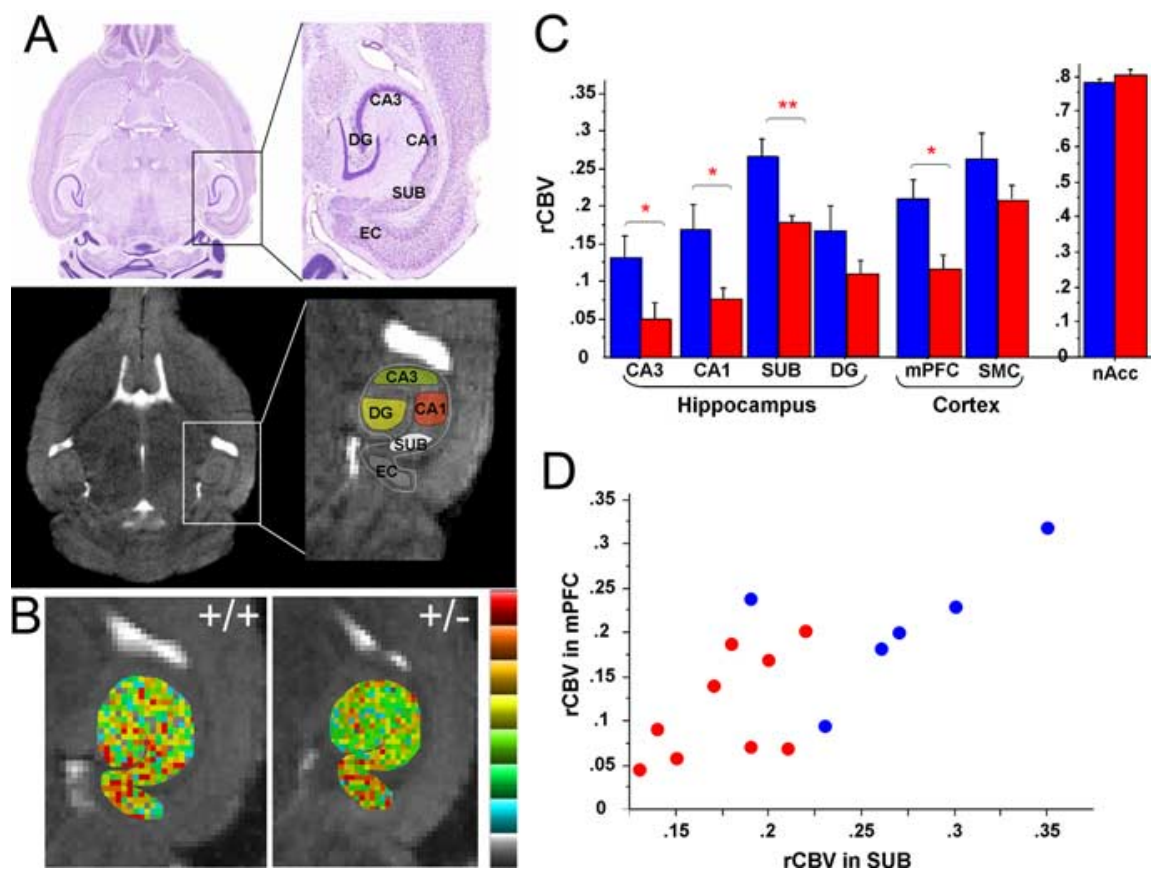

Figure 5. Type III Nrg1 heterozygous mice have lower function in subregions of hippocampus and in the medial prefrontal cortex.A, Horizontal brain sections (Paxinos and Franklin, 2004) (top panels) at the level of hippocampal subregions (marked and an enlarged view at the right panel): the entorhinal cortex (EC), the (A3 and CA1 subfields, the dentate gyrus (DG), and the subiculum (SUB). T2' axial MR images at similar anatomical positions as the top panels are shown at the bottom panels. Individual areas are circled according to their respective anatomical locations and used to determine the rCBV for each region. $\boldsymbol{B}$, MR images of one representative wild-type animal and one heterozygous animal $(+/+$ and $+/-)$ with the hippocampal subregions color coded such that warmer colors reflect higher rCBV values. Note the lower rCBV observed in the CA1 and subiculum subfields of the heterozygous, and higher rCBV observed in the wild-type animals. C, Basal measures of rCBV, a hemodynamic correlate of oxygen metabolism, were obtained from each hippocampal subregion, as well as medial prefrontal cortex, sensory and motor cortex, and the nucleus accumbens. Global decreases of rCBV were found in the CA1, subiculum, medial prefontal cortex, and to a lesser degree to the CA3 subfield in heterozygous mice (red) compared with their wild-type (blue) littermates $\left(n=6+/+\right.$ and $9+/-$; ANOVA test; ${ }^{*} p_{\text {genotype }}<0.05$ and $\left.{ }^{* *} p_{\text {genotype }}<0.01\right)$. Error bars indicate SEM. $\boldsymbol{D}$, Subiculum functions are correlated with medial prefrontal function. Blue indicates $+/+$, and red indicates $+/-$ animals.
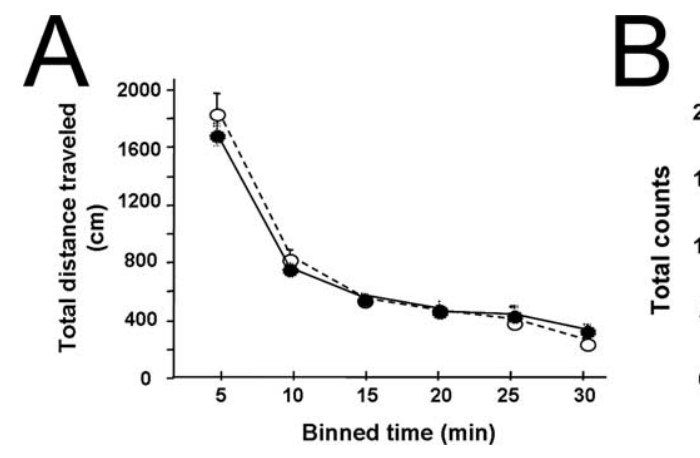

Figure 6. Locomotor activity of age-matched wild-type and type III Nrg1 heterozygous mice. $A$, Locomotor activity (mean \pm SEM) was measured as total distance traveled (in centimeters). $\boldsymbol{B}$, Total rears, total jumps, and total stereotypy in a novel open field. Seventeen WT mice $(+/+)$ versus 21 type III Nrg1 heterozygous $(+/-)$ mice were indistinguishable in general activity patterns within $30 \mathrm{~min}$ of being placed in the novel open field (5 min bins) (ANOVA: $F_{(1,36)}=0.94, p_{\text {genotype }}=0.34$ ). gating deficits. Chronic nicotine treatment increases PPI in type III Nrg1 $+/-$ mice.

We demonstrate that reduction in type III Nrg1/ErbB signaling results in specific defects from the cellular level to behavioral tests of frontal and temporolimbic corticostriatal circuits. Such specificity is evident in each set of data. For example, there were decreased spine densities in the proximal apical dendrites of subicular pyramidal neurons in type III Nrg1 +/- mice, but dendritic intersections, dendritic lengths, and distal spine densities were unchanged. This suggests that the effects of decreased type III Nrg1 may interact with synaptic contacts or other mechanisms that maintain spines of apical dendrites relatively proximal to the soma of subicular pyramidal neurons. The ventral subiculum serves as a major output pathway for cortical outputs of hippocampus (Naber et al., 2000; Witter, 2006). Neurons within the subiculum act as recipients and comparators receiving signals from prefrontal association cortices as well as thalamus (Lisman and Grace, 2005). The proximal apical dendrites of subicular pyramidal neurons receive inputs from the CA1; the distal apical dendrites receive inputs from the entorhinal cortex. Processed information is sent back from subicular pyramidal neurons to the entorhinal cortex, medial prefrontal cortex, ventral striatum, and other limbic structures (Naber et al., 1999, 2000, 2001). Interestingly, we found that functional activity, as measured by rCBV, of CA1, subiculum, and the medial prefrontal cortex are coordinately downregulated in type III Nrg1 +/- mice, whereas functional activity in the dentate gyrus, entorhinal cortex, ventral striatum (nucleus accumbens), and sensory/motor cortex are unchanged. The decreased functional profile is consistent with decreased spine density of the proximal regions of subicular pyramidal neurons (inputs from the CA1) and unchanged spine density in the distal regions (inputs from the entorhinal cortex) in type III Nrg1 +/- mice and is in agreement with the expression pattern of type III Nrg1 as well as its requirement for proper sensorimotor gating and short-term memory performance, both of which are sensitive to disruption in the prefrontal cortex and the is expressed in regions of the mouse brain that play critical roles in attention, sensorimotor gating, and working/short-term memory; (3) adult type III Nrg1 +/- mice have specific, quantifiable defects in CNS morphology and in behavior: type III Nrg1 $+/-$ mice have increased lateral ventricular volume and decreased spine densities on ventral subicular pyramidal neurons. Cerebral blood volume is decreased in the medial prefrontal cortex, CA1, and subiculum. Type III Nrg1 +/- mice are impaired in a working/short-term memory task and have sensorimotor ventral hippocampus (Caine et al., 1992; Lipska et al., 1995, 2002; Swerdlow et al., 1995; Moore et al., 2006).

Polymorphisms in the Nrg1 gene are associated with psychiatric disorders, such as schizophrenia, bipolar disorder, and lateonset Alzheimer's disease with psychosis (Stefansson et al., 2002; Go et al., 2005; Green et al., 2005; Harrison and Weinberger, 2005; Harrison and Law, 2006; Thomson et al., 2007). It has been proposed that altered expression of the NRG1 gene underlies the molecular mechanism by which polymorphisms in the NRG1 

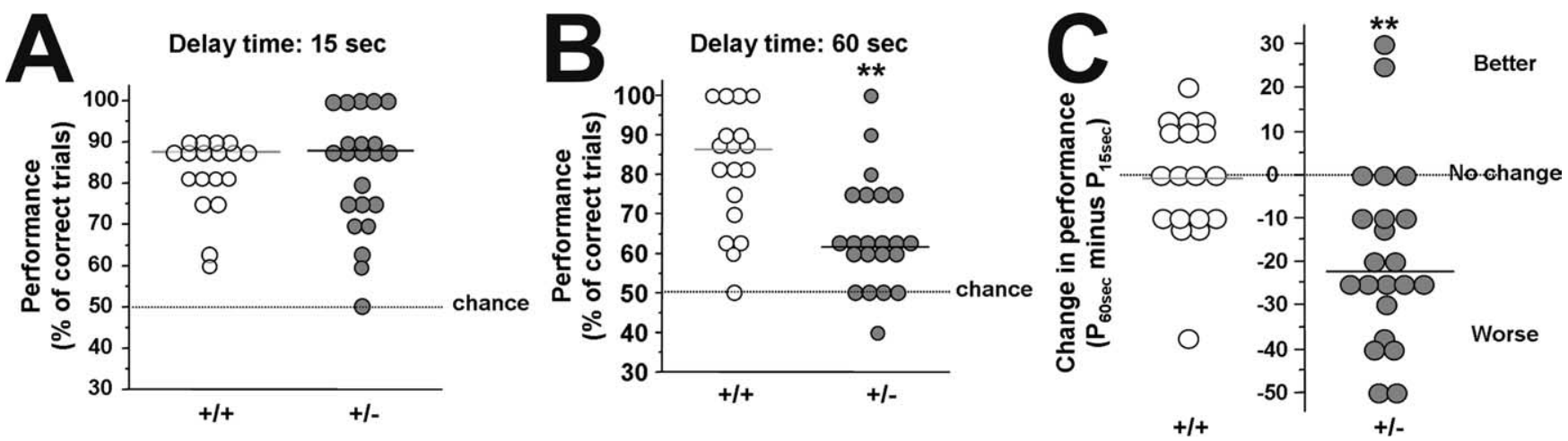

Figure 7. Type III Nrg1 heterozygous mice have impaired delayed alternation memory performance. $A, B$, Performance (percentage of correct trials) of 18 wild-type $(+/+)$ and 22 heterozygous $(+/-)$ animals in a continuous delayed alternation test using $15 \mathrm{~s}(\boldsymbol{A})$ or $60 \mathrm{~s}(\boldsymbol{B})$ as the delay time. Each point represents the average performance of $2 \mathrm{~d}$ testing from individual animals. The bold lines indicate the median (50th percentile). The dashed line indicates chance performance. There is a significant deterioration in performance of $+/-$ animals with $60 \mathrm{~s} \mathrm{delay} \mathrm{(Kolmogorov-Smirnov}$ test, $\left.\chi^{2}=11.1, p_{\text {genotype }}<0.008\right)$, whereas there is no difference between the performance of $+/+$ and $+/-$ mice with brief intertrial intervals $\left(15 \mathrm{~s}\right.$ delay: $\mathrm{K}-\mathrm{S}$ test, $\chi^{2}=2.0, p_{\text {genotype }}=$ $0.72) .{ }^{* *} p<0.01$. C, Scatter plots of the change in performance at 15 versus $60 \mathrm{~s}$ delay times for each animal. Positive values reflect better performance at $60 \mathrm{~s}$ compared with that at $15 \mathrm{~s}$; negative values reflect worse performance at 60 versus $15 \mathrm{~s}$. In $+1+$ animals, increasing the intertrial interval to $60 \mathrm{~s}$ resulted in little change in performance ( $p_{\text {delay time }}>0.8$ for wild type). In contrast, the same intertrial interval shift in $+/$ - animals resulted in decreased performance in 17 of the $22+/-$ mice. Heterozygote animals had a significant decrease in performance with increased intertrial time (Kolmogorov-Smirnov test: $\left.\chi^{2}=11.3 ; p_{\text {delay time }}<0.003\right)$. ${ }^{* *} p<0.01$.

locus lead to schizophrenia susceptibility (Stefansson et al., 2002; Harrison and Weinberger, 2005; Harrison and Law, 2006). Postmortem analyses demonstrate increased levels of type I or type IV Nrg1 transcripts in the dorsolateral prefrontal cortex (DLPFC) and the hippocampus (Hashimoto et al., 2004; Harrison and Law, 2006; Law et al., 2006) and altered levels of erbB4 splice variant transcripts in the DLPFC (Law et al., 2007), although it was also documented that neither $\mathrm{Nrg} 1$ nor ErbB4 protein was changed in postmortem tissues (Hahn et al., 2006). Brain slices from schizophrenics exhibited hyperresponsiveness to recombinant Nrg1 and hyporesponsiveness to glutamate receptor agonists (Hahn et al., 2006). It remains to be determined whether the downstream effects of increased type I/type IV expression, hyperresponsive ErbB4 signaling, and reduced type III Nrg1 expression converge to produce functional alterations associated with psychiatric disorders, and if so, how this occurs. One possibility is that increased paracrine signaling by soluble $\mathrm{Nrg} 1$ (presumably type I and type IV Nrg1) disrupts bidirectional, juxtacrine signaling mediated by type III Nrg1, resulting in excessive responses in ErbB-expressing neurons or glia and deficient responses in type III Nrg1-expressing neurons (Role and Talmage, 2007). Indeed, experimental disruption of juxtacrine signaling between peripheral axons and glia alters glial function, and contributes to demyelination, a phenotype that is replicated by type III Nrg1 +/- mice (Michailov et al., 2004; Taveggia et al., 2005; Tapinos et al., 2006).

Our observations in type III Nrg1 $+/-$ mice have parallels with findings in individuals with schizophrenia as well as in mouse models for schizophrenia (J. Chen et al., 2006; O'Tuathaigh et al., 2007a,b). The brain morphological changes in type III Nrg1 +/ - mice show similarities with changes seen in postmortem samples from schizophrenia (Degreef et al., 1992;

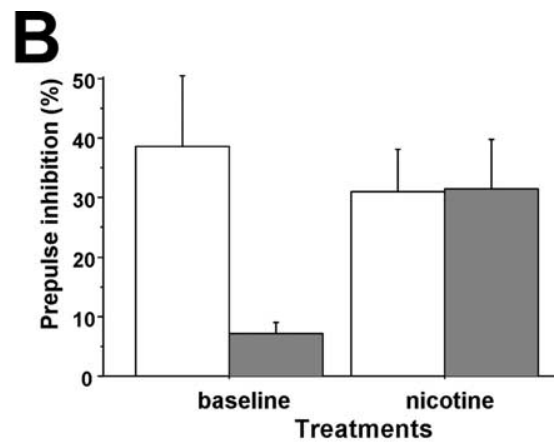

Figure 8. Type III Nrg1 heterozygous mice have prepulse inhibition deficits that are not seen if they have been treated with . A mixed-model, repeated-measure ANOVA indicated a statistically significant effect of prepulse intensity $\left(F_{(2,158)}=\right.$ wild-type and type III Nrg1 heterozygous mice ( $n=6 /$ genotype) before (baseline) and after 7 weeks of chronic nicotin startle stimuli as used in $A$. Therefore, the result of the baseline PPI in both genotypes was an independent replication of $A$ to detect the effects of chronic nicotine in both genotypes. A mixed ANOVA revealed a significant genotype by nicotine treatment effect $\left(F_{(1,10)}=5.63 ; p<0.04\right)$. The effects of genotype $\left(F_{(1,10)}=2.8 ; p=0.12\right)$ and nicotine $\left(F_{(1,10)}=1.54 ; p=0.24\right)$ were not significant. Before, but not after nicotine, the heterozygous mice had significantly reduced PPI values (before, $p<0.05$; after, $p=0.9$; Student's $t$ test with Scheffé's correction for multiple comparisons).

Glantz and Lewis, 2000; Rosoklija et al., 2000; Wright et al., 2000). Moreover, Nrg1 type III heterozygotes show impaired working memory and sensorimotor gating deficits, behavioral phenotypes associated with schizophrenia (Goldman-Rakic, 1999; Braff et al., 2001). Finally, high levels of cigarette smoking are prevalent in schizophrenics (Kumari and Postma, 2005; George et al., 2006), suggesting self-medication with nicotine (Kumari and Postma, 2005). Experimental administration of nicotine ameliorates working memory and PPI deficits in schizophrenia (Kumari and Postma, 2005; George et al., 2006; Postma et al., 2006). Thus, it is of interest that nicotine appears to normalize the PPI deficits in type III Nrg1 heterozygous mice.

The relationships between allelic variation on the NRG1 gene and vulnerability to developing schizophrenia remain to be determined. We believe animal models have the potential to pro- 
vide important insights into how alterations in the Nrg1/ErbB expression are related to the cognitive and affective deficits characteristic of schizophrenia. Several different Nrg1 mutant mice have been studied behaviorally (supplemental Table 2, available at www.jneurosci.org as supplemental material). These include type III Nrg1 specific mutants (Wolpowitz et al., 2000; this study), type I/type II mutants (generated by disruption of the Ig domains) (Kramer et al., 1996), transmembrane domain-deleted mutants (which affect types I, II, and III) (Stefansson et al., 2002), and pan-Nrg1 mutants (generated by deletion of EGF-like domain) (Meyer and Birchmeier, 1995) (Fig. 1).

In behavioral analyses, $\mathrm{TM}-\mathrm{Nrg} 1^{+/-}$and EGF-Nrg1 ${ }^{+/-}$mice were hyperactive in the novel open-field assay (Gerlai et al., 2000; Stefansson et al., 2002; Karl et al., 2007). In contrast, Ig-Nrg1 ${ }^{+/-}$ and CRD-Nrg1 ${ }^{+/-}$mice exhibit normal locomotor activity compared with wild-type controls (Rimer et al., 2005). TM-Nrg1 ${ }^{+/-}$ mice have weak PPI deficits, whereas $\mathrm{CRD}-\mathrm{Nrg} 1^{+/}$mice have strong PPI deficits (Stefansson et al., 2002). CRD-Nrg1 ${ }^{+/-}$mice have impaired performance in a short-term memory/working memory test, whereas $\mathrm{TM}-\mathrm{Nrg} 1^{+/-}$mice are unaffected in a spatial working memory test (O'Tuathaigh et al., 2007a). TM$\mathrm{Nrg} 1^{+/-}$mice are more aggressive toward an intruder mouse in the resident-intruder paradigm (O'Tuathaigh et al., 2007a); a behavior not seen in CRD-Nrg1 ${ }^{+/-}$mice (Y.-J. Chen, D. A. Talmage, and L. W. Role, unpublished observation).

Although some aspects of behavioral phenotypes in different $\mathrm{Nrg} 1$ isoform mutant mice are yet to be determined (supplemental Table 2, available at www.jneurosci.org as supplemental material), these distinct behavioral phenotypes are likely to reflect both differences in expression patterns, as well as distinct functional properties of different $\mathrm{Nrg} 1$ isoforms, as has been demonstrated in studies of myelination (supplemental Table 2, available at www.jneurosci.org as supplemental material) (Michailov et al., 2004; Taveggia et al., 2005; S. Chen et al., 2006). Resolution of the differences in the profiles of behavioral abnormalities in the Nrg1 mutant mice awaits detailed morphological, cellular, and physiological analyses of the underlying circuits.

These data, considered in the context of the other reports, broaden our understanding of $\mathrm{Nrg} 1$ in general and of the physiological functions of type III Nrg1, in particular. Normal levels of type III Nrg1 are required for normal corticolimbic circuits: decreased expression of type III Nrg1 leads to structural, functional, and behavioral alterations that are related to schizophrenia. More in-depth studies of $\mathrm{Nrg} 1 / \mathrm{ErbB}$ signaling in type III Nrg1 +/mice are needed to unravel the causal factors leading to schizophrenia susceptibility and to provide novel therapeutics for disease treatment.

\section{References}

Anton ES, Ghashghaei HT, Weber JL, McCann C, Fischer TM, Cheung ID, Gassmann M, Messing A, Klein R, Schwab MH, Lloyd KC, Lai C (2004) Receptor tyrosine kinase ErbB4 modulates neuroblast migration and placement in the adult forebrain. Nat Neurosci 7:1319-1328.

Aylward RL, Totterdell S (1993) Neurons in the ventral subiculum, amygdala and entorhinal cortex which project to the nucleus accumbens: their input from somatostatin-immunoreactive boutons. J Chem Neuroanat $6: 31-42$.

Bao J, Wolpowitz D, Role LW, Talmage DA (2003) Back signaling by the Nrg-1 intracellular domain. J Cell Biol 161:1133-1141.

Bao J, Lin H, Ouyang Y, Lei D, Osman A, Kim TW, Mei L, Dai P, Ohlemiller KK, Ambron RT (2004) Activity-dependent transcription regulation of PSD-95 by neuregulin-1 and Eos. Nat Neurosci 7:1250-1258.

Barbas H, Blatt GJ (1995) Topographically specific hippocampal projections target functionally distinct prefrontal areas in the rhesus monkey. Hippocampus 5:511-533.
Beracochea DJ, Jaffard R (1995) The effects of mammillary body lesions on delayed matching and delayed non-matching to place tasks in the mice. Behav Brain Res 68:45-52.

Braff DL, Geyer MA, Swerdlow NR (2001) Human studies of prepulse inhibition of startle: normal subjects, patient groups, and pharmacological studies. Psychopharmacology (Berl) 156:234-258.

Buonanno A, Fischbach GD (2001) Neuregulin and ErbB receptor signaling pathways in the nervous system. Curr Opin Neurobiol 11:287-296.

Caine SB, Geyer MA, Swerdlow NR (1992) Hippocampal modulation of acoustic startle and prepulse inhibition in the rat. Pharmacol Biochem Behav 43:1201-1208.

Carmichael ST, Price JL (1995) Limbic connections of the orbital and medial prefrontal cortex in macaque monkeys. J Comp Neurol 363:615-641.

Chen J, Lipska BK, Weinberger DR (2006) Genetic mouse models of schizophrenia: from hypothesis-based to susceptibility gene-based models. Biol Psychiatry 59:1180-1188.

Chen S, Rio C, Ji RR, Dikkes P, Coggeshall RE, Woolf CJ, Corfas G (2003) Disruption of ErbB receptor signaling in adult non-myelinating Schwann cells causes progressive sensory loss. Nat Neurosci 6:1186-1193.

Chen S, Velardez MO, Warot X, Yu ZX, Miller SJ, Cros D, Corfas G (2006) Neuregulin 1-erbB signaling is necessary for normal myelination and sensory function. J Neurosci 26:3079-3086.

Dalley JW, Cardinal RN, Robbins TW (2004) Prefrontal executive and cognitive functions in rodents: neural and neurochemical substrates. Neurosci Biobehav Rev 28:771-784.

Degreef G, Ashtari M, Bogerts B, Bilder RM, Jody DN, Alvir JM, Lieberman JA (1992) Volumes of ventricular system subdivisions measured from magnetic resonance images in first-episode schizophrenic patients. Arch Gen Psychiatry 49:531-537.

Engert F, Bonhoeffer T (1999) Dendritic spine changes associated with hippocampal long-term synaptic plasticity. Nature 399:66-70.

Falls DL (2003) Neuregulins: functions, forms, and signaling strategies. Exp Cell Res 284:14-30.

Flames N, Long JE, Garratt AN, Fischer TM, Gassmann M, Birchmeier C, Lai C, Rubenstein JL, Marin O (2004) Short- and long-range attraction of cortical GABAergic interneurons by neuregulin-1. Neuron 44:251-261.

George TP, Termine A, Sacco KA, Allen TM, Reutenauer E, Vessicchio JC, Duncan EJ (2006) A preliminary study of the effects of cigarette smoking on prepulse inhibition in schizophrenia: Involvement of nicotinic receptor mechanisms. Schizophr Res 87:307-315.

Gerecke KM, Wyss JM, Carroll SL (2004) Neuregulin-1beta induces neurite extension and arborization in cultured hippocampal neurons. Mol Cell Neurosci 27:379-393.

Gerlai R, Pisacane P, Erickson S (2000) Heregulin, but not ErbB2 or ErbB3, heterozygous mutant mice exhibit hyperactivity in multiple behavioral tasks. Behav Brain Res 109:219-227.

Geyer MA, Krebs-Thomson K, Braff DL, Swerdlow NR (2001) Pharmacological studies of prepulse inhibition models of sensorimotor gating deficits in schizophrenia: a decade in review. Psychopharmacology (Berl) 156:117-154.

Glantz LA, Lewis DA (2000) Decreased dendritic spine density on prefrontal cortical pyramidal neurons in schizophrenia. Arch Gen Psychiatry 57:65-73.

Glaser EM, Van der Loos H (1981) Analysis of thick brain sections by obverse-reverse computer microscopy: application of a new, high clarity Golgi-Nissl stain. J Neurosci Methods 4:117-125.

Glickstein SB, Hof PR, Schmauss C (2002) Mice lacking dopamine $\mathrm{D}_{2}$ and $\mathrm{D}_{3}$ receptors have spatial working memory deficits. J Neurosci 22:5619-5629.

Go RC, Perry RT, Wiener H, Bassett SS, Blacker D, Devlin B, Sweet RA (2005) Neuregulin-1 polymorphism in late onset Alzheimer's disease families with psychoses. Am J Med Genet B Neuropsychiatr Genet 139:28-32.

Goldman-Rakic PS (1999) The physiological approach: functional architecture of working memory and disordered cognition in schizophrenia. Biol Psychiatry 46:650-661.

Gonzalez RG, Fischman AJ, Guimaraes AR, Carr CA, Stern CE, Halpern EF, Growdon JH, Rosen BR (1995) Functional MR in the evaluation of dementia: correlation of abnormal dynamic cerebral blood volume measurements with changes in cerebral metabolism on positron emission tomography with fludeoxyglucose F 18. AJNR Am J Neuroradiol 16:1763-1770. 
Green EK, Raybould R, Macgregor S, Gordon-Smith K, Heron J, Hyde S, Grozeva D, Hamshere M, Williams N, Owen MJ, O’Donovan MC, Jones L, Jones I, Kirov G, Craddock N (2005) Operation of the schizophrenia susceptibility gene, neuregulin 1 , across traditional diagnostic boundaries to increase risk for bipolar disorder. Arch Gen Psychiatry 62:642-648.

Groenewegen HJ, Vermeulen-Van der Zee E, te Kortschot A, Witter MP (1987) Organization of the projections from the subiculum to the ventral striatum in the rat. A study using anterograde transport of Phaseolus vulgaris leucoagglutinin. Neuroscience 23:103-120.

Gu Z, Jiang Q, Fu AK, Ip NY, Yan Z (2005) Regulation of NMDA receptors by neuregulin signaling in prefrontal cortex. J Neurosci 25:4974-4984.

Hahn CG, Wang HY, Cho DS, Talbot K, Gur RE, Berrettini WH, Bakshi K, Kamins J, Borgmann-Winter KE, Siegel SJ, Gallop RJ, Arnold SE (2006) Altered neuregulin 1-erbB4 signaling contributes to NMDA receptor hypofunction in schizophrenia. Nat Med 12:824-828.

Harrison PJ, Law AJ (2006) Neuregulin 1 and schizophrenia: genetics, gene expression, and neurobiology. Biol Psychiatry 60:132-140.

Harrison PJ, Weinberger DR (2005) Schizophrenia genes, gene expression, and neuropathology: on the matter of their convergence. Mol Psychiatry 10:40-68.

Hashimoto R, Straub RE, Weickert CS, Hyde TM, Kleinman JE, Weinberger DR (2004) Expression analysis of neuregulin-1 in the dorsolateral prefrontal cortex in schizophrenia. Mol Psychiatry 9:299-307.

Holtmaat A, Wilbrecht L, Knott GW, Welker E, Svoboda K (2006) Experience-dependent and cell-type-specific spine growth in the neocortex. Nature 441:979-983.

Jay TM, Witter MP (1991) Distribution of hippocampal CA1 and subicular efferents in the prefrontal cortex of the rat studied by means of anterograde transport of Phaseolus vulgaris-leucoagglutinin. J Comp Neurol 313:574-586.

Jentsch JD, Tran A, Le D, Youngren KD, Roth RH (1997) Subchronic phencyclidine administration reduces mesoprefrontal dopamine utilization and impairs prefrontal cortical-dependent cognition in the rat. Neuropsychopharmacology 17:92-99.

Karl T, Duffy L, Scimone A, Harvey RP, Schofield PR (2007) Altered motor activity, exploration and anxiety in heterozygous neuregulin 1 mutant mice: implications for understanding schizophrenia. Genes Brain Behav 6:677-687.

Kitabatake Y, Hikida T, Watanabe D, Pastan I, Nakanishi S (2003) Impairment of reward-related learning by cholinergic cell ablation in the striatum. Proc Natl Acad Sci USA 100:7965-7970.

Kramer R, Bucay N, Kane DJ, Martin LE, Tarpley JE, Theill LE (1996) Neuregulins with an Ig-like domain are essential for mouse myocardial and neuronal development. Proc Natl Acad Sci U S A 93:4833-4838.

Kumari V, Postma P (2005) Nicotine use in schizophrenia: the self medication hypotheses. Neurosci Biobehav Rev 29:1021-1034.

Kwon OB, Longart M, Vullhorst D, Hoffman DA, Buonanno A (2005) Neuregulin-1 reverses long-term potentiation at CA1 hippocampal synapses. J Neurosci 25:9378-9383.

Law AJ, Lipska BK, Weickert CS, Hyde TM, Straub RE, Hashimoto R, Harrison PJ, Kleinman JE, Weinberger DR (2006) Neuregulin 1 transcripts are differentially expressed in schizophrenia and regulated by $5^{\prime}$ SNPs associated with the disease. Proc Natl Acad Sci USA 103:6747-6752.

Law AJ, Kleinman JE, Weinberger DR, Weickert CS (2007) Diseaseassociated intronic variants in the ErbB4 gene are related to altered ErbB4 splice-variant expression in the brain in schizophrenia. Hum Mol Genet 16:129-141.

Le Marec N, Ethier K, Rompre PP, Godbout R (2002) Involvement of the medial prefrontal cortex in two alternation tasks using different environments. Brain Cogn 48:432-436.

Li B, Woo RS, Mei L, Malinow R (2007) The Neuregulin-1 receptor ErbB4 controls glutamatergic synapse maturation and plasticity. Neuron 54:583-597.

Lipska BK, Swerdlow NR, Geyer MA, Jaskiw GE, Braff DL, Weinberger DR (1995) Neonatal excitotoxic hippocampal damage in rats causes postpubertal changes in prepulse inhibition of startle and its disruption by apomorphine. Psychopharmacology (Berl) 122:35-43.

Lipska BK, Aultman JM, Verma A, Weinberger DR, Moghaddam B (2002) Neonatal damage of the ventral hippocampus impairs working memory in the rat. Neuropsychopharmacology 27:47-54.

Lisman JE, Grace AA (2005) The hippocampal-VTA loop: controlling the entry of information into long-term memory. Neuron 46:703-713.
Liu Y, Ford B, Mann MA, Fischbach GD (2001) Neuregulins increase alpha7 nicotinic acetylcholine receptors and enhance excitatory synaptic transmission in GABAergic interneurons of the hippocampus. J Neurosci 21:5660-5669.

Longart M, Liu Y, Karavanova I, Buonanno A (2004) Neuregulin-2 is developmentally regulated and targeted to dendrites of central neurons. J Comp Neurol 472:156-172.

Lopez-Bendito G, Cautinat A, Sanchez JA, Bielle F, Flames N, Garratt AN, Talmage DA, Role LW, Charnay P, Marin O, Garel S (2006) Tangential neuronal migration controls axon guidance: a role for neuregulin-1 in thalamocortical axon navigation. Cell 125:127-142.

Ma J, Shen B, Rajakumar N, Leung LS (2004) The medial septum mediates impairment of prepulse inhibition of acoustic startle induced by a hippocampal seizure or phencyclidine. Behav Brain Res 155:153-166.

Masuda Y, Murai S, Saito H, Abe E, Itoh T (1992) A simple T-maze method for estimating working memory in mice. Effect of ethylcholine mustard aziridinium ion (AF64A). J Pharmacol Toxicol Methods 28:45-48.

Meyer D, Birchmeier C (1995) Multiple essential functions of neuregulin in development. Nature 378:386-390.

Meyer D, Yamaai T, Garratt A, Riethmacher-Sonnenberg E, Kane D, Theill LE, Birchmeier C (1997) Isoform-specific expression and function of neuregulin. Development 124:3575-3586.

Michailov GV, Sereda MW, Brinkmann BG, Fischer TM, Haug B, Birchmeier C, Role L, Lai C, Schwab MH, Nave KA (2004) Axonal neuregulin-1 regulates myelin sheath thickness. Science 304:700-703.

Moore H, Jentsch JD, Ghajarnia M, Geyer MA, Grace AA (2006) A neurobehavioral systems analysis of adult rats exposed to methylazoxymethanol acetate on E17: implications for the neuropathology of schizophrenia. Biol Psychiatry 60:253-264.

Moreno H, Hua F, Brown T, Small S (2006) Longitudinal mapping of mouse cerebral blood volume with MRI. NMR Biomed 19:535-543.

Naber PA, Witter MP, Lopez da Silva FH (1999) Perirhinal cortex input to the hippocampus in the rat: evidence for parallel pathways, both direct and indirect. A combined physiological and anatomical study. Eur J Neurosci 11:4119-4133.

Naber PA, Witter MP, Lopes Silva FH (2000) Networks of the hippocampal memory system of the rat. The pivotal role of the subiculum. Ann NY Acad Sci 911:392-403.

Naber PA, Lopes da Silva FH, Witter MP (2001) Reciprocal connections between the entorhinal cortex and hippocampal fields CA1 and the subiculum are in register with the projections from CAl to the subiculum. Hippocampus 11:99-104.

Okada M, Corfas G (2004) Neuregulin1 downregulates postsynaptic GABAA receptors at the hippocampal inhibitory synapse. Hippocampus 14:337-344.

O’Tuathaigh CM, Babovic D, O'Sullivan GJ, Clifford JJ, Tighe O, Croke DT, Harvey R, Waddington JL (2007a) Phenotypic characterization of spatial cognition and social behavior in mice with "knockout" of the schizophrenia risk gene neuregulin 1. Neuroscience 147:18-27.

O’Tuathaigh CM, Babovic D, O’Meara G, Clifford JJ, Croke DT, Waddington JL (2007b) Susceptibility genes for schizophrenia: characterisation of mutant mouse models at the level of phenotypic behaviour. Neurosci Biobehav Rev 31:60-78.

Ozaki M, Sasner M, Yano R, Lu HS, Buonanno A (1997) Neuregulin-beta induces expression of an NMDA-receptor subunit. Nature 390:691-694.

Paxinos G, Franklin KBJ (2004) The mouse brain in stereotaxic coordinates, Ed 2. Amsterdam, Boston: Elsevier Academic.

Pereira AC, Huddleston DE, Brickman AM, Sosunov AA, Hen R, McKhann GM, Sloan R, Gage FH, Brown TR, Small SA (2007) An in vivo correlate of exercise-induced neurogenesis in the adult dentate gyrus. Proc Natl Acad Sci USA 104:5638-5643.

Postma P, Gray JA, Sharma T, Geyer M, Mehrotra R, Das M, Zachariah E, Hines M, Williams SC, Kumari V (2006) A behavioural and functional neuroimaging investigation into the effects of nicotine on sensorimotor gating in healthy subjects and persons with schizophrenia. Psychopharmacology (Berl) 184:589-599.

Rieff HI, Raetzman LT, Sapp DW, Yeh HH, Siegel RE, Corfas G (1999) Neuregulin induces $\mathrm{GABA}_{\mathrm{A}}$ receptor subunit expression and neurite outgrowth in cerebellar granule cells. J Neurosci 19:10757-10766.

Rimer M, Barrett DW, Maldonado MA, Vock VM, Gonzalez-Lima F (2005) Neuregulin-1 immunoglobulin-like domain mutant mice: clozapine sensitivity and impaired latent inhibition. NeuroReport 16:271-275. 
Role LW, Talmage DA (2007) Neurobiology: new order for thought disorders. Nature 448:263-265.

Rosoklija G, Toomayan G, Ellis SP, Keilp J, Mann JJ, Latov N, Hays AP, Dwork AJ (2000) Structural abnormalities of subicular dendrites in subjects with schizophrenia and mood disorders: preliminary findings. Arch Gen Psychiatry 57:349-356.

Roy K, Murtie JC, El-Khodor BF, Edgar N, Sardi SP, Hooks BM, BenoitMarand M, Chen C, Moore H, O’Donnell P, Brunner D, Corfas G (2007) Loss of erbB signaling in oligodendrocytes alters myelin and dopaminergic function, a potential mechanism for neuropsychiatric disorders. Proc Natl Acad Sci USA 104:8131-8136.

Sarter M, Hasselmo ME, Bruno JP, Givens B (2005) Unraveling the attentional functions of cortical cholinergic inputs: interactions between signal-driven and cognitive modulation of signal detection. Brain Res Brain Res Rev 48:98-111.

Schmid RS, McGrath B, Berechid BE, Boyles B, Marchionni M, Sestan N, Anton ES (2003) Neuregulin 1-erbB2 signaling is required for the establishment of radial glia and their transformation into astrocytes in cerebral cortex. Proc Natl Acad Sci USA 100:4251-4256.

Shaw C, Aggleton JP (1993) The effects of fornix and medial prefrontal lesions on delayed non-matching-to-sample by rats. Behav Brain Res 54:91-102.

Sheng M, Hoogenraad CC (2007) The postsynaptic architecture of excitatory synapses: a more quantitative view. Annu Rev Biochem 76:823-847.

Small SA (2003) Measuring correlates of brain metabolism with highresolution MRI: a promising approach for diagnosing Alzheimer disease and mapping its course. Alzheimer Dis Assoc Disord 17:154-161.

Stefansson H, Sigurdsson E, Steinthorsdottir V, Bjornsdottir S, Sigmundsson T, Ghosh S, Brynjolfsson J, Gunnarsdottir S, Ivarsson O, Chou TT, Hjaltason O, Birgisdottir B, Jonsson H, Gudnadottir VG, Gudmundsdottir E, Bjornsson A, Ingvarsson B, Ingason A, Sigfusson S, Hardardottir H, et al. (2002) Neuregulin 1 and susceptibility to schizophrenia. Am J Hum Genet 71:877-892.

Steinthorsdottir V, Stefansson H, Ghosh S, Birgisdottir B, Bjornsdottir S, Fasquel AC, Olafsson O, Stefansson K, Gulcher JR (2004) Multiple novel transcription initiation sites for NRG1. Gene 342:97-105.

Swerdlow NR, Lipska BK, Weinberger DR, Braff DL, Jaskiw GE, Geyer MA (1995) Increased sensitivity to the sensorimotor gating-disruptive effects of apomorphine after lesions of medial prefrontal cortex or ventral hippocampus in adult rats. Psychopharmacology (Berl) 122:27-34.

Tapinos N, Ohnishi M, Rambukkana A (2006) ErbB2 receptor tyrosine ki- nase signaling mediates early demyelination induced by leprosy bacilli. Nat Med 12:961-966.

Taveggia C, Zanazzi G, Petrylak A, Yano H, Rosenbluth J, Einheber S, Xu X, Esper RM, Loeb JA, Shrager P, Chao MV, Falls DL, Role L, Salzer JL (2005) Neuregulin-1 type III determines the ensheathment fate of axons. Neuron 47:681-694.

Thomson PA, Christoforou A, Morris SW, Adie E, Pickard BS, Porteous DJ, Muir WJ, Blackwood DH, Evans KL (2007) Association of Neuregulin 1 with schizophrenia and bipolar disorder in a second cohort from the Scottish population. Mol Psychiatry 12:94-104.

van Zijl PC, Eleff SM, Ulatowski JA, Oja JM, Ulug AM, Traystman RJ, Kauppinen RA (1998) Quantitative assessment of blood flow, blood volume and blood oxygenation effects in functional magnetic resonance imaging. Nat Med 4:159-167.

Verma A, Moghaddam B (1996) NMDA receptor antagonists impair prefrontal cortex function as assessed via spatial delayed alternation performance in rats: modulation by dopamine. J Neurosci 16:373-379.

Vinogradova OS (2001) Hippocampus as comparator: role of the two input and two output systems of the hippocampus in selection and registration of information. Hippocampus 11:578-598.

Wang JY, Miller SJ, Falls DL (2001) The N-terminal region of neuregulin isoforms determines the accumulation of cell surface and released neuregulin ectodomain. J Biol Chem 276:2841-2851.

Witter MP (2006) Connections of the subiculum of the rat: topography in relation to columnar and laminar organization. Behav Brain Res 174:251-264.

Wolpowitz D, Mason TB, Dietrich P, Mendelsohn M, Talmage DA, Role LW (2000) Cysteine-rich domain isoforms of the neuregulin-1 gene are required for maintenance of peripheral synapses. Neuron 25:79-91.

Woo RS, Li XM, Tao Y, Carpenter-Hyland E, Huang YZ, Weber J, Neiswender H, Dong XP, Wu J, Gassmann M, Lai C, Xiong WC, Gao TM, Mei L (2007) Neuregulin-1 enhances depolarization-induced GABA release. Neuron 54:599-610.

Wright IC, Rabe-Hesketh S, Woodruff PW, David AS, Murray RM, Bullmore ET (2000) Meta-analysis of regional brain volumes in schizophrenia. Am J Psychiatry 157:16-25.

Yang X, Kuo Y, Devay P, Yu C, Role L (1998) A cysteine-rich isoform of neuregulin controls the level of expression of neuronal nicotinic receptor channels during synaptogenesis. Neuron 20:255-270.

Zuo Y, Yang G, Kwon E, Gan WB (2005) Long-term sensory deprivation prevents dendritic spine loss in primary somatosensory cortex. Nature 436:261-265. 